\title{
Welfare Reform and Children's Early Cognitive Development
}

\begin{abstract}
In this paper, we use a dynamic structural model to measure the effects of (i) single mothers' work and welfare use decisions and (ii) welfare reform initiatives on the early cognitive development of the children of the National Longitudinal Survey of Youth 1979 mothers. We use standardized PIAT math test scores as a measure of attainment. We find that both work and welfare use by mothers' before children turn six have positive impacts on children's cognitive development.However, these benefits decline as children's observed innate ability increases and vary by the mother's attitudes towards welfare receipt and work, and by her child-rearing technology. In the case of welfare use, for example, the effect can be negative if the mother has a favorable view of welfare use or less welfare stigma, indicated by continuous welfare utilization. We find that a policy change similar to the welfare time limit and work requirement introduced by the welfare reform reduces use of welfare and increases employment significantly. This policy change, however, only slightly increases test scores. We also look at the implications of an exemption from welfare tax on labor income and a maternal leave policy on children's outcomes.
\end{abstract}

Keywords: Welfare reform, childhood cognitive development, female work, dynamic choice model, maximum likelihood

JEL codes: I38, J22, J18 


\section{Introduction}

In 1996, the Personal Responsibility and Work Opportunity Reconciliation Act (PRWORA) ended Aid for Families with Dependent Children (AFDC), replacing it with the new Temporary Assistance for Needy Families (TANF) program. PRWORA was the culmination of many earlier changes to welfare policy in several states aimed at increasing employment among welfare recipients and reducing dependence on welfare programs. The TANF program nationalized these changes and ended the entitlement period of welfare by introducing work requirements and a 5-year time limit on welfare benefits. In this paper, we use a dynamic structural model to analyze the impact of welfare reform on the early cognitive development of the children of those who choose to take welfare assistance. Using a sample of low-skilled single mothers and their children from the NLSY79 data, we first estimate the effects of mothers' work and welfare use on children's cognitive development. We can then simulate the time limit and work requirement policies introduced by PRWORA. With the simulated data we evaluate how these policy changes impact the work and welfare participation behaviors of mothers and, as a result, children's early cognitive development. We also analyze possible effects on early cognitive development of an exemption of welfare tax on labor income and a maternity leave policy.

Early cognitive development has been found to be a strong predictor of long-term achievement and other outcomes. In particular, early test scores are strongly correlated with educational attainment, crime involvement, salaries and out-of-wedlock pregnancy (see reviews by Duncan and Brooks-Gunn, 1997; Haveman and Wolfe, 1995; and Currie and Thomas, 1995). Therefore, it is crucial to understand whether welfare policies affect children's early cognitive outcomes. Additionally, because parental time and financial resources are likely to be the most important components of early nurturing, any public policy that affects parents' incentives to work or participate in welfare, and change the opportunity costs of these inputs, should be carefully evaluated.

This paper adds to two strands of literature: (i) behavioral responses to welfare reform and (ii) determinants of children's early cognitive development. Despite an abundance of 
studies on the effects of welfare reform on mothers' behaviors, proper attention has not been given to the possible impacts that such behavior and welfare reform may have on children. Except for a very recent paper by Miller and Zhang (2009), to our knowledge, there is no other study that directly looks at the effects of welfare reform on children's outcomes. Miller and Zhang (2009) analyze the effects of welfare reform on the math test scores of fourth and eighth graders in a difference-in-difference framework. Using high-income children as controls, they find that welfare reform has no negative impact on children's long-term math ability outcomes. In fact, they show that welfare reform narrow the gap in the scores of high-income and low-income children. In two related papers, Bernal and Keane 2010 and 2011 use the variation in welfare rules generated by the welfare reform and by earlier state-level waivers to identify the effects of child care on children's cognitive outcomes. Even though they did not directly study welfare reform, in light of their estimates for marginal effects for child care use, these papers imply negative effects of welfare reform on children's cognitive development.

To the best of our knowledge, we are the first to perform a structural analysis of this subject. This analysis allows us to model multiple mechanisms that affect the monetary and other inputs of welfare participants. It further allows us to perform policy simulations to capture the extent to which each individual component of welfare reform contributes to changes in children's outcomes. Moreover, we look at the effects of welfare reform on early cognitive development outcomes, taken before the start of children's formal schooling. Our findings complement Miller and Zhang's in that we find a positive association between children's cognitive development and mothers' employment and welfare use.

We contribute to the literature on the determinants of children's achievement in three ways. First, the effects of a mother's decisions in our attainment-production function are allowed to interact with the child's (observed) innate ability, which is determined by a set of time-invariant factors of the child. This setup allows us to obtain distributions for the effects of work and welfare by children's innate ability, in addition to a single coefficient that measures only the effects at the mean level. To our knowledge, our model is one of 
only a few that allows for this flexibility. Bernal (2008) and Bernal and Keane(2010 and 2011)discuss the importance of allowing the marginal effects of a mother's decisions to vary with the child's (observed) innate ability. These papers study the effects of mothers' child care use and work decisions on their children's test scores. They find that the marginal effects of a mother's choices decrease with the increase in the innate ability of the child. That is, although the effects on a child with the mean innate ability may be small and positive, there are significantly larger positive impacts for children at the low end of the innate ability distribution and large negative effects for those at the high end. We follow a similar setup to construct our attainment-production function. Our second contribution to the literature lies in our modeling strategy. Our model, motivated by Bernal (2008) $)^{1}$, assumes that a child's attainment, observed at the end of age five, is determined by the cumulative welfare use and work experiences of the first five years after birth. Using data from multiple periods enables us to identify the effects using a much richer variation in mothers' decisions. Moreover, it allows us to investigate the implication of different "intensity"levels of work and welfare use.

Our third contribution is that through our modeling strategy, we are able to better disentangle the various effects from factors that are proxied by mothers' decisions. Following Chyi and Ozturk(2012), we model multiple channels through which a mother's decisions can affect a child's attainment: direct monetary benefits, parental time invested in the child and nonpecuniary benefits from in-kind transfer programs. Furthermore, we also allow the mother's attitude towards welfare program participation to be correlated with her child rearing technology, which helps us to explain why, in the data, mothers who use more welfare tend to have children with worse outcomes than children born to otherwise similar mothers. The estimates hence provide a deeper understanding of the workings of both AFDC and TANF.

Most studies on the relationship between welfare participation and early cognitive achievement focus either on the determinants of children's attainment or on the conse-

\footnotetext{
${ }^{1}$ Bernal and Keane(2010 and 2011)also use this model
} 
quences of growing up in poor families. In both areas, researchers use samples that are restricted to children available in survey data sets and tend to employ an ordinary least squares (OLS) method for estimation. They generally find significantly negative relationships between welfare receipt and various types of child attainment measures. As has been pointed out before (see Currie, 1998; Duncan, Magnuson and Ludwig, 2004; and Dahl and Lochner, 2005), these negative relationships do not necessarily indicate causal connections, mostly because of improper comparison groups or the unobserved heterogeneity issue.

In this paper, we use the variation in AFDC cash benefits across U.S. states as well as county-level information to alleviate the concern of unobserved heterogeneity. Moreover, to avoid improper group comparison, we focus only on the attainment of children born to single mothers with twelve or fewer years of schooling. Such mothers are most likely to satisfy the financial eligibility requirement for welfare programs. ${ }^{2}$ As a result, rather than making comparisons with children from economically stable, two-parent families that do not qualify for welfare, we measure the effects of welfare by ascertaining the difference in attainment between welfare recipients and eligible nonparticipants.

Our estimates suggest that mothers have an incentive to invest more in children with lower innate ability. Furthermore, single mothers' employment in the first five years of their children's lives has positive effects on children's cognitive development, but these benefits decline with an increase in the children's innate ability. The marginal effect of an additional year of employment on a child with median ability is an increase of about 0.426 percent of his or her test score. ${ }^{3}$ To analyze the effect of mothers' welfare use on children's attainment, we allow heterogeneity in terms of taste for welfare use and child rearing technology. Our estimates suggests two types of mothers: Mothers with low taste for welfare use and good child rearing technology, and mothers with high taste for welfare and bad technology. For a mother, who prefers less welfare use and

\footnotetext{
${ }^{2}$ We can theoretically define our sample using the exact financial eligibility of welfare based on each individual's information. However, a sample based on financial eligibility creates a potential selection problem because earnings is an outcome of the endogenous work decision.

${ }^{3}$ The PIAT Math test score has a mean of 100 and a standard deviation of 15 .
} 
has good rearing technology, the net marginal effect of an additional year of welfare is positive. For a child with median ability, this welfare participation benefit is $2.2 \%$ per year. While for a median ability child with a mother who has low welfare stigma and bad technology to rear her child, this effect is 0.417 percent per year. The marginal effect of welfare use by this type of mother can become even negative if the child is endowed with higher than median innate ability. It is worth noting that our positive employment effects are significantly different from previous literature which documents negative cognitive achievement responses to the employment of mothers from two-parent, less economically vulnerable families. We take this as evidence that for children who grew up in families headed by low-skilled single mothers, the benefits of mothers' employment outweigh the detrimental effects.

We find that for a child who has the median level of observed innate ability, policies that reduce welfare use and/or increase employment are beneficial to that child's early cognitive achievement. Specifically, our counterfactual policy simulations suggest that a policy that combines a work requirement and a two-year welfare time limit that is similar to the current welfare reform initiatives reduces a single mother's use of welfare and increases the incidence of employment. Our result shows that this combination of both initiatives significantly increases the child's test score by about 1.8 percent. Following an initiative that is adopted by many state waiver programs, we also simulate an exemption in the welfare tax on labor income. The simulated policy practice sharply increases work decisions without changing welfare participation patterns. Consequently, the simulated test score for a median child increases by only about 0.42 percent.

In addition to these counterfactual analysis that mimics the welfare reform, we simulate several new policy changes that have not been implemented but may be of interest to policy makers including a maternity leave policy and welfare tax relief on labor income. A maternity leave policy reduces employment by 9 percentage points but increases welfare participation by about 6 percentage points. This policy eventually decreases log test scores by about 0.68 percent on average. By eliminating welfare tax on labor income we 
can increase work in this population by about 6 to 12 percentage points: a very significant change in work behavior. This will result in 0.46 percent increase in the log mean test score.

The structure of the paper is as follows. The next section proposes an economic model of a child's attainment production. Section 2.2 discusses the econometric estimation of this model and the identification of parameters. Section 3 describes the data used in the analysis, while Sections 4 and 5 report the estimation results. Section 6 concludes.

\section{Model}

Our model is closely related to that of Bernal (2008), in which mothers are the sole decision makers of the family. We model a mother's annual welfare and work participation decisions for the first five years following her child's birth. ${ }^{4}$ In each period, her utility is comprised by her consumption of leisure, a composite good and her child's current level of potential attainment. She observes her child's innate ability and produces the child's current attainment by contributing monetary and non-monetary resources through her work and welfare use decisions. At the age of the first PIAT-Math test, we observe a test score that proxies the cognitive attainment as a function of observed innate ability, cumulative welfare use, employment history and income. This is traditionally how human capital formulation is devised as proposed by Ben-Porath (1967), where cumulative investment determines human capital.

A mother is assumed to know the level of innate ability a child is born with. Econometricians, however, can only infer the level by time-invariant variables observed at the time of child's birth. The so-called observed innate ability $\left(A_{0}\right)$ is determined by two things. The first is the child's own characteristics, including birth weight and dummy variables indicating race $(\mathrm{Black}=1)$ and gender $($ girl $=1) .^{5}$ The second is inherited abil-

\footnotetext{
${ }^{4}$ In fact, in the model we also make use of the information of her decisions from two years prior to her child's birth, but these decisions are treated as given.

${ }^{5}$ Race and gender are included in the innate ability function purely for simplicity. We expect girls and
} 
ity as determined by mother's accumulated human capital, proxied by her Armed Forces Qualification Test (AFQT) percentile score, number of years of education, age at birth and years of work and welfare participation prior to giving birth. ${ }^{6}$ It can be written as:

$$
\begin{gathered}
\ln A_{0}=\gamma_{6} \text { birth weight }+\gamma_{7} \text { gender }+\gamma_{8} \text { race }+\gamma_{9} \text { ageless } 18+\gamma_{10} \text { agemore } 33 \\
+\gamma_{11} \text { edu }+\gamma_{12} \text { AFQT }+\gamma_{13} \text { prior welfare }+\gamma_{14} \text { prior work }
\end{gathered}
$$

Both prior work and welfare variables are dummy variables indicating whether a mother has welfare use and work experiences in the two years prior to her child's birth. The effect of a mother's age at childbirth on innate cognitive ability is characterized by two dummy variables that equal to 1 either when a mother is younger than 18 (ageless 18 ) or when she is older than 33 (agemore 33). These indicators capture the increased possibility of health problems for children born to young mothers and complications for geriatric pregnancy that may lead to lower cognitive scores. ${ }^{7}$

A mother produces her child's current cognitive achievement by investing money (from labor and welfare incomes) and non-monetary resources. For example, mothers spend time taking care of their children and also provide their children a role model in their daily lives. As our population consists of low-income children, their mothers can also choose to participate in Medicaid or take up free child care through the welfare program. However, these non-monetary inputs are not directly observed in the data. We use work and welfare use decisions as proxy variables to capture their effects. Later, we boys to be affected by maternal inputs in different ways. Moreover, we expect cultural differences with respect to family structure, child care choice and breastfeeding behavior across races. These factors are shown to be important contributors to cognitive development. By incorporating these fixed factors into the innate ability function, we reduce the number of parameters to be estimated significantly while capturing potential differences between different racial backgrounds and genders.

${ }^{6}$ This strategy to capture the children's unobserved ability endowment is also used in Bernal (2008) and Bernal and Keane (2010 and 2011). These variables merely reflect correlations rather than causal relationships.

${ }^{7} \mathrm{We}$ try including a variable measuring a mother's age at birth together with age dummies. However, the estimated coefficient is not statistically significant. We suspect that the effect may have been absorbed by other maternal characteristics such as years of education or the age dummy itself. Thus, we do not use this variable in $\ln A_{0}$. 
discuss specific channels through which mothers' work and welfare use decisions affect children's attainments. The log of a child's attainment $\left(A_{t}\right)$ is

$$
\ln A_{t}=\ln A_{0}+\gamma_{1} \ln \frac{Y_{t}}{N_{t}}+\gamma_{2} E_{t}+\gamma_{3} W_{t}+\gamma_{4} \ln A_{0} W_{t}+\gamma_{5} \ln A_{0} E_{t},{ }^{8}
$$

where $Y_{t}$ is income accumulated thus far since childbirth. As we do not model a mother's childbearing decision, we calculate the average income spent on each child by dividing $Y_{t}$ by the number of children $(N)$ at year $t .{ }^{9} Y_{t}=\sum_{s=1}^{t}\left(h_{s} Y_{s}^{L}+\omega_{s} B_{s}+Y_{s}^{O}\right)$ represents available financial resources, which is the sum of labor earnings ( $Y^{L}>0$ if working), welfare benefits $\left(B>0\right.$ if on welfare) and other income $\left(Y^{O}\right) .{ }^{10}$

$E_{t}$ and $W_{t}$ are the cumulative work and welfare use $t$ years after the child's birth, respectively. ${ }^{11} E_{t}=\sum_{s=1}^{t} h_{s}$ where $h_{s}=0,1$, or 2 if the mother is not employed, employed part-time or full-time in year $s$, respectively. Similarly, $W_{t}=\sum_{s=1}^{t} \omega_{t}$, where $\omega_{s}=0$ if the mother is not on welfare at year $s, 1$ otherwise.

By adding interactions between the mothers' decisions and the observed innate ability, we allow for possible differential effects of the mothers' decisions by observed innate ability. In other words, a child's innate ability can affect the returns for the mother's various inputs in the production of current cognitive ability. To simplify the matter, we

\footnotetext{
${ }^{8} \mathrm{~A}$ small but interesting point is whether we should include a constant term in $\ln A_{0}$. Since we include the main effects of work and welfare, $\gamma_{2}$ and $\gamma_{3}$ in $\ln A_{t}$, respectively, adding a constant term in $\ln A_{0}$ will not provide further economic information on a mother's child rearing technology.

${ }^{9}$ Although the average observed number of children in our sample is 2.4 , modeling childbearing decisions is outside the scope of this paper. As a result, we treat the number of children as given, and treat children born to the same mother as independent observations. Bernal (2008) and Bernal and Keane (2010 and 2011) use a similar treatment.

${ }^{10}$ Note that cumulative income itself is a function of mothers' decisions. Initially, income is allowed to interact with $\ln A_{0}$ to capture the potential effects of income on children with the observed innate ability. Since the estimated coefficient of a such model is not significant, we drop this interaction term for simplicity.

${ }^{11}$ We assume that only the cumulative years matter. Bernal (2008) and Bernal and Keane (2010 and 2011) have a similar setup. A different modeling strategy is based on the timing of investment (see for example, Brooks-Gunn, Han and Waldfogel, 2002 and an excellent review by Todd and Wolpin, 2003). In such a model, inputs made by the mother at the child's different ages may have different effects on the child's potential achievement. The empirical results of a such model using our sample (not presented but available upon request) show that none of the coefficients is significant.
} 
assume the child's cognitive ability is known to the mother at any point in time (but not observed by the econometrician). We can only observe the outcomes of a test the child is given as a part of a survey, from which ability is inferred. This outcome function will be discussed in detail in Section 2.2.3. The outcome measures we adopt come from the Children of the National Longitudinal Survey of Youth (NLSY) 1979 cohort (Children of NLSY79). The standardized Peabody Individual Achievement Tests (PIAT) are given to the Children of NLSY79 sample from age five onwards. We use the mathematics (PIATMath) test scores as the outcome measure primarily because they have been shown to be predictors of not only later math scores but also other academic achievement (for example see Claessens, Duncan and Engel, 2009 and Duncan et al., 2007). ${ }^{12}$

As mentioned before, a mother's work and welfare use experiences during her child's childhood serve as proxy variables for non-monetary inputs that cannot be measured directly. After laying down the attainment production function, it is useful to discuss the channels through which a mother's welfare and work decisions affect her child's attainment, and what is captured by the coefficients of $W_{T}, E_{T}$, and $Y$ in Equation (2). Welfare can affect the attainment of a child in three ways: (i) income, (ii) time spent with the child and (iii) non-cash benefits through related programs. First, any income effects are captured by the coefficient of $\frac{Y_{t}}{N_{t}}$. Second, a mother may choose to substitute welfare for work so that she can invest more time in her child's nurturing. This effect will be captured by a decrease in maternal employment, $E_{t}$. Thus, the welfare coefficient captures only the contributions of the nonpecuniary benefits of being on welfare. Many meanstested transfer programs are linked with AFDC (and now with TANF), such as the early childhood education program, Head Start, housing subsidies and the Medicaid health insurance program. As we do not separately control for participation in different programs that are linked with AFDC (according to Currie (1998), it is almost impossible to do so), the benefits on a child's attainment from these programs are captured by the coefficient of

\footnotetext{
${ }^{12}$ To increase the sample size, Bernal (2008) and Bernal and Keane (2010 and 2011) incorporate the PIATMath, PIAT-Reading and Peabody Picture Vocabulary Test (PPVT) scores to form an outcome measure. In other words, in these papers each individual child can potentially be counted in the estimation up to three times.
} 
the welfare use history, $W_{t}$.

Additionally, mothers' employment decisions can affect ability through (i) income, (ii) time spent with the child and (iii) other work-related activities that may affect children's outcomes. The first effect is captured by the coefficient of average income. The second and third effects are captured by the coefficient of $E_{T}$. We can think of two possible consequences of this effect. On the one hand, work picks up the effects of the unobserved lost time for a mother to educate or care for her child and may thus be detrimental to a child's attainment. Morrill (2009) shows that a mother's employment increases the probability of poor health outcomes for 7- to 17-year-olds, which is probably true for younger children as well. In fact, although indirectly through child care and as a function of supervision, Baker, Gruber, and Milligan (2008) and Curie and Hotz (2004) show that increases in mothers' employment heighten the probability of injuries and poor health outcomes in kindergarten-aged children, which may in turn affect their cognitive development (see, for example, Blau and Grossberg, 1992). On the other hand, children's attainment can improve when, for instance, working mothers provide a positive role model for them to follow. Both the sociology and psychology literature commonly argue the role model effect to be strong. Also, according to Cascio (2009), low-income mothers are more likely than married women to put their children in kindergarten, perhaps because kindergarten is, among other things, 100 percent subsidized day care. If working mothers' children, who are placed in kindergarten, have access to educational tools in the classroom that are not available in the home environment, as is very likely the case for disadvantaged families, we may observe a positive relationship between a child's attainment and the mother's employment. Our outcome measures take place before children go to elementary school. As a result, low-skilled mothers' employment can capture the benefits obtained from subsidized child care. ${ }^{13}$ Unless we are willing to make more structural assumptions on how a mother takes care of her child, the two opposite effects

\footnotetext{
${ }^{13}$ However, as Cascio and Schanzenbach (2007) and Bedard and Dhuey (2006) point out, this could lower the school entry age for disadvantaged children, which might be detrimental because younger children tend to perform worse than older children in most school cohorts. This may suggest that the short-run benefit may not last long.
} 
will be both captured by the coefficient of $E_{T}$ in Equation (2). It becomes an empirical question as to which effect dominates.

\subsection{Mother's Optimization Problem}

In each period (year), a mother makes two decisions: whether to participate in welfare $\left(I^{W}\right)$ and how much to work $(h)$. Welfare choice is defined as a binary variable, and work choice is set as able to have three possibilities: working full-time (at least 1,500 hours a year, that is, at least 30 hours a week for 50 weeks), working part-time (between 500 hours (at least 10 hours a week for 50 weeks) and 1499 hours per year), and not working (less than 500 hours per year). As a result, in each year, a mother chooses from six alternatives, which can be formally written as $J=\left\{\left(h_{t}, I_{t}^{w}\right): h_{t}=0,1,2 ; I_{t}^{w}=0,1\right\}$. We use an indicator function, $d_{j}$, to represent the alternatives that are chosen, where $j=1, . ., 6$. To clarify, $j=1$ corresponds to $\left(h_{t}, I_{t}^{w}\right)=(0,0)$, meaning that a mother chooses (no work, no welfare) in period $t ; j=2$ represents $\left(h_{t}, I_{t}^{w}\right)=(1,0)$ (part-time, no welfare); $j=3$

represents $\left(h_{t}, I_{t}^{w}\right)=(2,0)$ (full-time, no welfare), and so forth. $d_{j}=1$ indicates that alternative $j$ is chosen. With this setup, we estimate the joint probability distribution of the mother's work and welfare participation decisions.

In each period, the state vector $S_{t}$ includes work experience $E_{t}$ and cumulative welfare usage $W_{t}$ up to the current year. As we also make use of the information of a mother's work and welfare use decisions for the two years prior to her child's birth, the state vector 
evolves in the following manner: ${ }^{14}$

$$
\begin{aligned}
& E_{1}=h_{-1}+h_{-2} \\
& E_{t}=E_{t-1}+h_{t-1} \\
& W_{1}=I_{-1}+I_{-2} \\
& W_{t}=W_{t-1}+I_{t-1}^{W},
\end{aligned}
$$

where $h_{t-1}$ and $I_{t-1}^{W}$ are the work and welfare choices in the previous periods, respectively. Facing a given state vector $S_{\tau}$ at the beginning of a specific period $\tau$, a mother makes choices for periods from $\tau$ on (i.e., she chooses $d_{t}^{j}$ for $\left.t=\tau, \tau+1, \ldots, 5\right)$ to maximize her expected utility of the remaining periods, which we call $V_{\tau} . V_{\tau}$ is the (maximized) sum of a mother's current-period utility and discounted future utility, both of which depend on which alternative of $j$ she chooses for the current period that also maximizes $V_{\tau}$.

Defining a current-period, alternative-specific utility, $u\left(S_{t}, j, \epsilon_{j t}\right)$, as the sum of a deterministic part $U_{t}^{j}$ and an alternative-specific shock $\epsilon_{j t}$, we have:

$$
u\left(S_{t}, j, \epsilon_{j t}\right)=u\left(S_{t}, j\right)+d_{j t} \epsilon_{j t}=U_{t}^{j}+d_{j t} \epsilon_{j t},
$$

where $\epsilon_{j t}$ is assumed to be i.i.d. across time. With $S_{t}, j$ and discount rate $\beta$, we can write $V_{t}$ as

$$
V_{t} \equiv V\left(S_{t}, \epsilon_{j t}\right)=\max _{d_{j t}}\left\{V^{j}\left(S_{t}, j\right)+d_{j t} \epsilon_{j t}\right\}
$$

where $V^{j}\left(S_{t}, j\right)$ is given by the recursive form

$$
V^{j}\left(S_{t}, j\right)=U_{t}^{j}+\beta \sum_{S^{\prime}} \operatorname{Pr}\left(S^{\prime} \mid S, j\right) E V\left(S^{\prime}, \epsilon^{\prime}\right) \cdot{ }^{15}
$$

\footnotetext{
${ }^{14}$ Notice that initial conditions $E_{1}$ and $W_{1}$ are predetermined because they depends only on information before a child's birth, which is taken as given.

${ }^{15}$ Note that in our setup of transition of state variables, Equation $\sqrt{3}, \operatorname{Pr}\left(S^{\prime} \mid S, j\right)$ is deterministic.
} 
The solution method for the mother's optimization problem is a standard backward induction. To refer to it, see Appendix A.1.

\subsection{Empirical Implementation}

This section lists our empirical specifications and discusses their economic implications. We structurally estimate the parameters of these functions.

\subsubsection{Mother's Current Period Utility Function}

The mother's current-period utility of choosing alternative $j \in J$ is given by

$$
\begin{aligned}
U\left(S_{t}, j, \epsilon_{j t}\right)=\frac{1}{\alpha_{1}} c_{j t}^{\alpha_{1}}+\alpha_{2} h_{t} & +\alpha_{3}\left(\frac{A_{t}^{\lambda}-1}{\lambda}\right)+\alpha_{4} I_{t}^{W}+\alpha_{5} I\left(W_{t}=0\right) \\
& +\alpha_{6} I\left(E_{t}=0\right)+\alpha_{7} I_{1}^{h}+\epsilon_{j t}
\end{aligned}
$$

where $c_{t}$ is composite consumption, $h_{t}$ is the mother's current work decision, $A_{t}$ is the child's current-period potential cognitive attainment. $I_{t}^{h}$ and $I_{t}^{w}$ are the indicators for work and welfare participation in period t. $W_{t}$ and $E_{t}$ are accumulated work and welfare experience from the two periods before giving birth until the beginning of the current period.

We normalize the utility unit of the composite consumption to one. As a result, utilities of the remainders in the function are measured relative to the value of the composite consumption good. Parameters $\alpha_{2}$ and $\alpha_{4}$ are distastes for work and welfare, respectively. ${ }^{16}$ The mother cares about her child's attainment as it increases her current period utility. This is captured by $\alpha_{3}$, which should be a positive number. Parameter $\alpha_{5}$ captures the additional disutility incurred when applying for welfare for the first time, ${ }^{17}$ and $\alpha_{6}$

\footnotetext{
${ }^{16}$ It is worth mentioning here that we allow the taste of welfare use $\left(\alpha_{4}\right)$ to vary according to the type of mothers. See further discussion in Section 2.2.4.

${ }^{17}$ This assumption is consistent with the concept of welfare stigma pioneered by Moffitt (1983).
} 
is the cost of initiating work if one has never worked before. $\alpha_{7}$ is added to capture the extra cost if a mother chooses to work during the first year after giving birth $(t=1){ }^{18}$ The utility function is constant relative risk averse (CRRA) both in terms of consumption and child's cognitive achievement. For example, by CRRA, $\lambda<1$ means that the mother receives diminishing returns to the child's achievement and thus has a higher incentive to compensate her child with lower innate ability.

The composite consumption good is determined by the current-period income obtained through the budget constraint

$$
c_{j t}=w_{t} h_{t}+B_{j t} I_{t}^{W}+M_{t}
$$

in which $w_{t}$ is the offered wage, $B_{j t}$ is the dollar amount of welfare transfer for that year and $M_{t}$ is the non-labor and non-welfare income. As our population focuses on poor families with little to save, we choose not to model saving decisions. Given that the sample families have very low income, not modeling saving decisions should not be very restrictive.

\subsubsection{Wage Equation}

The log of the mother's current-period wage is determined by a set of time-invariant characteristics, including race, age at childbirth, age squared, number of years of education ,AFQT score, and decisions made in the last period as follows:

$$
\begin{aligned}
\ln w_{t}= & \phi_{1} a g e+\phi_{2} a g e^{2}+\phi_{3} \text { race }+\phi_{4} e d u c+\phi_{5} A F Q T+\phi_{6} \\
& -\delta t+\phi_{7} E_{t}+\phi_{8}\left(E_{t} \times e d u c\right)+\phi_{9} p_{t-1}+\phi_{10} f_{t-1}+\phi_{11} L_{s t}+\xi_{t}
\end{aligned}
$$

\footnotetext{
${ }^{18}$ This parameter captures the psychological cost of separation from the child when the child is very young. In practice, labor force participation in the first year will be slightly overestimated if we do not include $\alpha_{7}$ in the estimate.
} 
where $\delta$ is the depreciation rate. $E_{t}=\sum_{-2}^{t-1} h_{\tau}$ is the mother's cumulative work experience since the two periods prior to giving birth, and $f_{t-1}$ and $p_{t-1}$ indicate whether a mother has worked full-time or part-time during the immediately preceding period, respectively. The county-level labor market quality measure (the county unemployment rate, employment share in services sector and average wage level) is $L_{s t}$, where $s$ is the county in which the mother and her child reside at time $t$. Finally, $\xi_{t}$ is the random shock that is assumed to be i.i.d normal. Even though this assumption is not crucial in estimations, it simplifies the estimation and the simulations.

\subsubsection{Child's Cognitive Attainment}

We do not directly observe a child's cognitive attainment $\left(A_{t}\right)$. Instead, we use the child's test score observed after a child has turned six as a proxy. All children in the NLSY have taken several cognitive achievement tests biannually, starting from when each child turned six. We make use of the PIAT-Math as the outcome measure. ${ }^{19}$ Whenever a test score is observed, the outcome (test score, $\ln O_{t}$ ) of the child can be written as

$$
\ln O_{t}=\ln A_{t}+\gamma_{15} t+\mu_{0}+\nu_{t}
$$

where $t$ is the child's age (in months) when we observe the child's first test score. ${ }^{20} \mu_{0}$ is the mean test score and $\nu_{t}$ is the random disturbance drawn from a normal distribution with mean of zero, and a variance of $\sigma_{\nu}^{2}$. Together with Equation 2, the output production

\footnotetext{
${ }^{19}$ We choose mathematical attainment because it has shown to be mostly closely related to a child's later cognitive achievement (see for example, Claessens, Duncan and Engel, 2009). Bernal (2008) and Bernal and Keane (2010 and 2011) assume three outcomes, PIAT-Math, PIAT-Reading and PPVT, are produced by the same production function. In other words, a sample child can be used in the estimation at most three times. They add two dummy variables in the outcome production function to separate which particular test they use as dependent variable. In the context of a production function, such practice does not distinguish the possibility that mothers' same decisions can have potentially different effects on children's different cognitive attainments (saved for a level-shifter).

${ }^{20}$ Although the PIAT tests are given to each child biannually from age five onwards, some of the first observed test scores are from later ages.
} 
function can be written as follows:

$$
\ln O_{t}=\ln A_{0}+\gamma_{1} \ln \frac{Y_{t}}{N_{t}}+\gamma_{2} E_{t}+\gamma_{3} W_{t}+\gamma_{4} \ln A_{0} W_{t}+\gamma_{5} \ln A_{0} E_{t}+\gamma_{6} t+\mu_{0}+\nu_{t}
$$

This equation, together with Equation 1, shows that, for example, the difference between the mean test scores of males and females, everything else equal, can be captured by $\gamma_{8}+\gamma_{4} \gamma_{8} E_{t}+\gamma_{5} \gamma_{8} W_{t}$. This captures the possibility that a female child may have a different early cognitive development experience compared to a male child especially in households headed by a single mother. Time spent with the mother may stimulate girls more compared to boys. Moreover, when the mother is working, child care choices may affect boys and girls differently due to different gender socialization patterns. Similar expressions can be derived for race and the mother's characteristics at birth. By potentially capturing unobserved social and developmental characteristics, these variables help us control for the variation in cognitive development in response to the mother's work patterns and welfare use.

\subsubsection{Unobserved Heterogeneity in Two Dimensions}

In our setup, mothers are heterogeneous in terms of their tastes of work and welfare use. In particular, $\alpha_{2}$ and $\alpha_{4}$, the utility function parameters regarding work and welfare use, are determined by the (observed and unobserved) accumulated human capital at the time of their children's birth. Furthermore, we also assume mothers to be heterogeneous in their unobserved tastes for welfare utilization, which separates mothers into "high type"(type 
I) and "low type"(type II). ${ }^{21}$ Specifically, $\alpha_{2}$ and $\alpha_{4}$ are specified as

$$
\begin{aligned}
\alpha_{2} & =\alpha_{21} e d u c+\alpha_{22} r a c e+\bar{\alpha}_{2} \\
\alpha_{4 k} & =\alpha_{41} e d u c+\alpha_{42} r a c e+\bar{\alpha}_{4 k}, k=L, H,
\end{aligned}
$$

where $\bar{\alpha}_{4 k}$ is the unobserved component of taste for welfare use. We assume that there are two different types (low, $\bar{\alpha}_{4 L}$, and high, $\bar{\alpha}_{4 H}$ ).

Furthermore, we assume that mothers with different tastes for welfare use also have available different technologies in rearing their children. In particular, we link $\gamma_{3}$, the production function parameter regarding welfare use in Equation (7), with the two types of welfare tastes: $\gamma_{3 H}$ for a Type I mother and $\gamma_{3 L}$ for a Type II mother. ${ }^{22}$ Associated type proportions are denoted by $\pi_{H}$ and $\pi_{L}$, which are parameters to be estimated. ${ }^{23}$

Note that the marginal effect of a mother's welfare use on her child's attainment is

$$
\frac{\partial O_{t}}{\partial W_{t}}=\gamma_{3}+\gamma_{4} \ln A_{0}
$$

By adding unobserved types on $\gamma_{3}$, we allow for the intercept of the marginal effect of welfare use to be different. However, we assume the interaction between mothers with different welfare use types and children with different observed innate ability to be the same. It is also possible to link $\gamma_{4}$ with welfare types. As the empirical difference is small, we omit it for simplicity.

\footnotetext{
${ }^{21}$ Unlike Bernal (2008), we only base types on mothers' welfare use decisions. As a result, work decisions of mothers with different unobserved tastes in welfare use differ only through potentially different income resources. We have tried to impose unobserved heterogeneity on work taste here, but upon controlling for the unobserved welfare taste, unobserved type parameters for work become unstable and insignificant in magnitudes.

${ }^{22}$ Note that although $\gamma_{3}$ is linked with $\alpha_{4}$, we allow the data to tell us whether $\gamma_{3 H}>\gamma_{3 L}$. That is, we do not restrict that a mother who has lower welfare stigma $\left(\alpha_{4 L}\right)$ would use welfare-related non-cash benefits less efficiently in investing in her child's cognitive development.

${ }^{23}$ We choose not to link $\ln A_{0}$ with $\alpha_{4}$. In other words, we assume mothers of different tastes in welfare use can give birth to children with the same observed ability, so long as their observed covariates are identical.
} 
As a side note, we also choose not to allow the technology on using income $\left(\gamma_{1}\right)$ of mothers of different types to vary. The reason is that after meeting basic survival needs, poor families may not have extra monetary resources to invest in their children's cognitive development. This is confirmed as $\hat{\gamma}_{1}$ is not statistically significant.

In the following sections we explain the econometric model and the estimation.

\subsection{The Likelihood Function}

The individual likelihood function for individual $i$ at time $t$ with type $k$ can be written as

$$
L_{i t k}=\left\{\sum_{k}^{I, I I} \pi_{k}\left[\sum_{j=1}^{J} d_{j} \operatorname{Pr}\left(d_{j}=1 \mid S_{t}, k\right) g\left(O_{t} \mid k\right)^{I\left[O_{t} \text { available }\right]}\right]\right\} f\left(w_{t} \mid S_{t}\right)^{I\left[h_{t}>0\right]}
$$

where $f\left(w_{t} \mid S_{t}\right)^{I\left(h_{t}>0\right)}$ is the probability of receiving a wage offer at $w_{t}$ if the mother is working, conditional on the work experience and other state variables. $g\left(O_{t} \mid k\right)^{I\left[O_{t} \text { available }\right]}$ is the probability of observing the test score $O_{t}$ when a test is given to a child with a type $k$ mother at time $t$. The product of $L_{i t k}$ across years gives us the individual likelihood function. The natural logarithm of the product of individual likelihoods gives the log likelihood function.

We estimate our model using the maximum likelihood (ML) method. We write $V_{t}^{j}$ as the value function of choice $\mathrm{j}$ in period $\mathrm{t}$, and we need to solve it before we can compute $\operatorname{Pr}\left(d_{j}=1 \mid S_{t}, k ; \theta\right)$. Given state variable $S_{t}$ and the alternative-specific error term $\epsilon_{t}^{j}$, we know that

$$
V^{j}\left(S_{t}, k, \epsilon_{t}^{j}, \theta\right)=u_{t}^{j}+\beta \int_{\epsilon^{\prime}} \max \left(V^{1}, V^{2}, \ldots, V^{J}\right) d F\left(\epsilon^{\prime}\right)
$$

The problem can then be solved by backward induction, as discussed in Appendix A.1. We assume that the preference shocks $\epsilon$ are drawn i.i.d. from the Type I extreme value dis- 
tribution with a location parameter of 0 and a scale parameter of 1 . This enables us to write the probability of choosing $d_{j}$, given state $S_{t}$, as $\operatorname{Pr}\left(d_{j}=1 \mid S_{t}, k\right)=\frac{\exp \left(V^{j}\left(S_{t}, k, d_{j}\right)\right)}{\sum_{k} \exp \left(V^{k}\left(S_{t}, k, d_{j}\right)\right)}$.

\subsection{Identification}

The variation of benefits across states is often utilized in the literature to identify the effects of AFDC on work and welfare use behavior (see a complete review in Moffitt, 2002). In this paper, we follow the same strategy. Furthermore, we also incorporate county labor market information, measured by the county-level unemployment rate, employment share in the service section and average wage level, as further sources of exogenous variation.

The benefit rule for the AFDC program of each state is a nonlinear function of a mother's income, work decisions, and number of children she has. Keane and Wolpin (2002) find that empirical results vary widely in the literature mostly due to the adoption of different benefit-rule parameters. They argue that the benefit level of a specific year fails to capture the long-term changes in state AFDC rules, which are more likely to affect mothers' decisions in a dynamic setting. Instead of using randomly drawn, real benefit levels, they suggest that researchers should estimate the long-term state-benefit rules and use the estimated parameters as instruments.

Following the strategy of Keane and Wolpin (2002), we estimate the AFDC benefit rules for each U.S. state by pooling all single-mother welfare receipts in the Panel Study of Income Dynamics (PSID) from 1968 to 1992 and using dummy variables to identify state benefit parameters. The AFDC benefit for a mother $i$ who lives in state $s$ is given by the equation:

$$
\begin{aligned}
B_{i s}= & b_{0}+\left(b_{2}+\sum_{s} b_{3 s} D_{s}\right) \cdot n o C_{i}+\left(b_{4}+\sum_{s} b_{5 s} D_{s}\right) \cdot n o C S q_{i} \\
& +\left(b_{6}+\sum_{s} b_{7 s} D_{s}\right) M_{i}+\left(b_{8}+\sum_{s} b_{9 s} D_{s}\right)\left(w_{i} h_{i}\right)
\end{aligned}
$$


where $D_{s}$ is the indicator of the residence of individual $i . D_{s}=1$ if mother $i$ lives in state $s . n o C_{i}$ is the number of children in the household and $n o C S q_{i}$ is the square of this number. $M_{i}$ is the unearned income and $w_{i} h_{i}$ is the labor income of the individual.

\section{Data and Sample}

The population of focus is children who were born to low-skilled single mothers. The data come from Children of NLSY79. As most children start school at either age five or six, we focus only on the first five years of cognitive development. During these early years, the mother's time, money and other inputs should have the most direct impact on the child. The original data is recorded on a quarterly basis, but is converted into yearly data for the purposes of the analysis. To measure attainment we make use of the standardized math scores of the Peabody Individual Achievement Test. Since 1986, the PIAT has been assessed biannually and given repeatedly to NLSY children from the age of five. We use a child's first observed math test scores to measure short-term attainment. PIAT standardized test scores range from 65 to 135 with a mean of 100 and a standard deviation of 15 based on the 1968 national norm sample of children. ${ }^{24}$

The NLSY mother-child pair sample is constructed on the basis of the following criteria: (i) a child's mother must have always been single within the first five years after childbirth, ${ }^{25}$ (ii) the mother must have recoverable information for the first five years of the child's life, and (iii) the child must have at least one valid PIAT-math test score. Given that we do not model initiatives of welfare reform at this point, we exclude children who reside in U.S. states that implemented any state waiver programs or welfare reform during their childhoods.

\footnotetext{
${ }^{24}$ PIAT test scores are known to have a potential "cohort effect." Namely, latter cohorts have higher mean test scores than previous cohorts. We deal with this issue by adding a cohort mean, $\mu_{t}$, to the outcome, Equation (7).

${ }^{25}$ Initially we include "sometimes single" mothers in our sample and also include the number of years each mother was single as a control variable. Since the results are not significantly different, we exclude these women from the final version of our analysis.
} 


\subsection{Sample Description}

In our sample, we have 2,820 observation-years from 564 children who were born to 392 single mothers $(15,640$ quarters in the original data). Table 1 reports the mean values of the variables used in our analysis. The first panel of this table lists the means of work and welfare variables in the first five years after birth. Defined as having reported positive welfare income for more than one quarter in a year, the childhood welfare participation rate of this group of children is 79.4 percent. Of our sample, 12.8 percent of the mothers worked part-time during their children's childhood, whereas 18.6 percent of them worked full-time. In other words, the labor force participation rate for this group of low-skilled mothers is roughly 31.4 percent. The sample of children consists of a nearly equal share of males and females. Our sample is predominantly black (74 percent). The average PIAT-math score is 93.1, which is significantly lower than the mean test score of the 1968 norm population. This is indicative of the disadvantage of growing up poor. On average, women are about 25.5 years old at the birth of their child. This is younger than the NLSY79 mothers' average age of 27. Sample mothers, on average, have 10.9 years of education and two children. Also, those who have worked receive a mean annual labor income of \$10,737 (in 2000 dollars). The AFQT score used in the analysis is a percentile score. Table 1 indicates that our average mother is at the 14th percentile of the AFQT distribution, corresponding to a raw score of about 140. (AFQT raw scores vary between 80 and 320.)

We also consider three county-level characteristics to determine labor market quality while estimating the initial and current wages. ${ }^{26}$ These are shown in table 1 , which reports that our sample mothers tend to live in counties with higher unemployment rates (the average unemployment rate in these counties is 7.9 percent while the comparable national average is 6.8 percent), high shares of service industry (the average share of service industry in the sample states is 16.5 percent, and the national average is 15.8 percent), and

\footnotetext{
${ }^{26} \mathrm{We}$ follow children who were born in different calendar years from birth to age six. The county-level and national statistics reported here are the means over the first five years of each child's life across all sample children.
} 
low median income (the median income in the sample counties is $\$ 23,967$, whereas the national average for the same period is $\$ 27,019) .{ }^{27}$

Table 2 further distinguishes a mother's welfare use and work decisions according to her child's age. Because pre-birth decisions are incorporated as the initial state variables, the table contains information starting from two years before a child's birth. Comparing pre- and post-birth welfare use, we note that single mothers have increased welfare use by a minimum of 10 percentage points due to giving birth to a new child. Labor force participation only seems to be affected in the first year after childbirth. In fact, mothers' mean hours of work (conditional on having work) increase significantly after their children turn one-year-old.

We take a closer look at the distribution of individual characteristics and distribution of test scores by these characteristics in Table 3. From this table, we first see that more than 75 percent of the children who were raised by low-skilled single mothers score below the population mean (100) because the mean test score of the third quartile is only 93.3. Next, for each of the variables used in the analysis, we report the quartile means and for each of these quartiles we report the mean test score observed. For example, the second quartile mean of real hourly wages is $\$ 2.60$. For children whose mothers' wages fall into this quartile, the mean test score is 92.4. The distributions of children's test scores based on different quartiles of labor and other incomes indicate that there is not a close connection between children's childhood financial wellbeing and their test scores. ${ }^{28}$

The next set of mothers' characteristics, shown in Table 3, are AFQT score, education level, ${ }^{29}$ and age at childbirth. Given our sampling strategy, no mothers in our sample received more than twelve years of schooling. We divide our sample into two groups,depending upon their years of education, fewer than twelve years and exactly

\footnotetext{
${ }^{27}$ All monetary variables are adjusted to year 2000 dollars by the Personal Consumption Expenditure Deflator for nondurable goods (PCED-nondurable).

${ }^{28}$ To get a measure of general financial wellbeing while children grow up, we take an average of the wage and income measures over the study period. Other income is defined as annual family income minus labor and welfare income (welfare income includes AFDC and food stamps benefits).

${ }^{29}$ This is measured at the child's birth. We exclude all mothers who were in school during the sampling window.
} 
twelve years, and summarize children's test scores accordingly. One can see that there is a significant positive correlation between a mother's AFQT scores and her child's test scores and between a mother's education level and her child's test scores. In terms of age at birth, the descriptive statistics seem to suggest that children of older mothers tend to have lower scores. However, as will be seen later in the same table, this correlation may be explained by the fact that older mothers also tend to have more children, and hence fewer resources available for each child.

The next group of variables is children's characteristics, including race, gender and number of siblings. Even though all of the sample children grew up in disadvantaged backgrounds, Black and Hispanic children have lower test scores than their non-Black, non-Hispanic counterparts. Also, girls perform better than boys, on average. In terms of numbers of siblings, we divide the children into five groups by number of siblings: children with no sibling, with one sibling, with two siblings, with three siblings, and with more than three siblings. We see a negative correlation between a child's PIAT-math test score and number of siblings. For example, children with no siblings have a mean test score of 95.7 , but the mean score of children with more than three siblings is just 90.2. As a result, this variable seems to have captured the effect of defused resources that an economically constrained mother can invest in each of her children. We also summarize children's test scores by their ages taking the test. As can be seen, there does not exist a significant correlation between age when taking the test and test scores. This is reasonable, as the standardized test score we use has already adjusted for this factor. Finally, we look at the test score distribution based on the county unemployment rate, employment ratio of the service industry workers and medium income level. Again, there is no clear pattern between these county characteristics and resident children's test scores. 


\section{Results}

\subsection{Parameter Estimates}

The subjective depreciation rate $(\beta)$, and depreciation of human capital $(\delta)$ are not estimated with the main model. We adopt these two values from Bernal (2008). $\beta$ is set at 0.92 , while $\delta$ is set at $0.003 .{ }^{30}$ Except for these two values, we structurally estimate the remaining parameters in the wage equation, the mother's utility function and the child's cognitive achievement equation.

Table 4 lists the estimates of Equation 5, the log-wage function. The coefficients are all in the expected directions. Both work experiences (part-time and full-time) by themselves and the interaction of them with education increase hourly wages, whereas a higher unemployment rate in a county is associated with lower wage. Conversely, a higher county service employment ratio and mean income are positively correlated with local wage offers. According to the estimates, an extra year of work increases wages by one percentage point, which is quite similar to estimates from the literature.

Table 5 reports the estimates of utility function parameters, demonstrated by Equation (4). We find that $\lambda$ is 0.52 , which indicates that a mother has an incentive to invest more in a child with lower cognitive development. A mother's taste for work $\left(\alpha_{2}\right)$ is captured by a term that is invariant to everyone $\left(\overline{\alpha_{2}}\right)$, her years of education, and her ethnicity. The estimates suggest that mothers generally value leisure ( $\overline{\alpha_{2}}$ is negative). Mothers who have more years of education tend to dislike work more, which is also found by Bernal (2008). Furthermore, we find that on average, Black mothers receive slightly higher utility from work than their counterparts. ${ }^{31}$

\footnotetext{
${ }^{30}$ For the discount factor $(\beta)$ however, we convert Bernal's quarterly discount rate $(0.98)$ to the annual rate, which is 0.92 .

${ }^{31}$ However, this positive coefficient is far from enough to outweigh the negative utility of work from other components in $\alpha_{2}$. Bernal (2008) finds that compared to mothers of other ethnicities, Black mothers perceive a larger negative utility from work. However, Bernal also finds that Black mothers receive a higher positive utility from using child care. The combined effect of the two decisions is that Black mothers receive a positive utility from working and using child care simultaneously. Since we do not model child care use
} 
We also find that a mother receives a significantly positive utility from her child's cognitive achievement (a highly positive $\alpha_{3}$ ), which is quite reasonable. ${ }^{32}$ In the utility function, $\alpha_{4}$ captures the negative utility from using welfare in each period. We allow $\alpha_{4}$ to vary across individuals by years of education, ethnicity and also by attitude towards welfare (as high-stigma mothers [Type I] and low-stigma mothers[Type II]). As can be seen from the estimates, other things equal, mothers who are better educated are more inclined to use welfare (if they are eligible). Also, Black mothers have a higher welfare stigma than mothers of other ethnicity. On the other hand, there are indeed two very distinctive types in terms of welfare stigma $\left(\overline{\alpha_{4 H}}\right.$ and $\left.\overline{\alpha_{4 L}}\right)$. Mothers with higher welfare stigma receive three times higher the utility cost (-2.07 as opposed to -0.65$)$ from using welfare than their counterparts. We will discuss the implications of welfare types in detail in Section 4.3 ,

In the mother's utility function, there are three initiation costs: first-time using welfare after the child's birth $\left(\alpha_{5}\right)$, first job since giving birth $\left(\alpha_{6}\right)$ and working in the first year after child's birth $\left(\alpha_{7}\right)$. We see that mothers receive a negative $\alpha_{5}$ that is higher than all $\alpha_{4}$ combined. As a result, we know mothers not only receive negative utility from using welfare, but also a much higher disutility from initiating it. This explains why many eligible single mothers choose not to participate in the welfare program. On the other hand, both $\alpha_{6}$ and $\alpha_{7}$ are negative. This reflects the fact that many mothers chose not to work in the first year after their children's birth.

The main set of parameters we are interested in is the achievement production function parameters, Equation (7), which is reported in Table 6. Note that the coefficients here refer to the child's log achievement (log-standardized PIAT-Math test score). First, we discuss estimates that comprise the observed innate ability $\left(\ln A_{0}\right)$. This is captured by a set of observed time-invariant factors, including the child's birth weight, gender, eth-

decisions, our work decision may have captured the average utility effects from both employment and child care use decisions.

${ }^{32}$ Note that our cognitive achievement term, $\ln A_{t}$, does not have a constant term. The constant term is added in the outcome equation, Equation (7). It affects the relative scale of $\alpha_{3}$ but does not change the qualitative result. 
nicity, whether the mother gave birth before age 18 (mother's too young) or after age 33 (mother's too old), her number of years of education and her AFQT score. We also include whether the mother has prior welfare and work experiences before the child's birth in the observed innate ability function. The estimates are all in the direction we have seen in the literature (and in particular, Bernal (2008) and Bernal and Keane (2010 and 2011)). For example, birth weight is highly positively correlated with the observed test score. On average, girls perform better than boys. Both the mother's number of years of education and her AFQT score are highly correlated with the child's test score. Additionally, while whether a mother was too young when giving birth is not statistically correlated with the child's test score, being born to a mother who is older is positively correlated with the child's observed innate ability. Also, having no prior welfare experiences and more prior work experiences are significantly associated with a higher observed innate ability.

In terms of the effects of the mother's work and welfare use decisions, we focus on the marginal effects of an additional year of a mother's decisions on her child's test score. In our setup, marginal effects of work $(E)$ and welfare use $(W)$ on the cognitive outcome depend on a child's innate log-achievement level, $\ln A_{0}$. The effect of employment on a child's cognitive achievement is assumed to be homogeneous in our model, which is $\frac{\partial \ln O}{\partial \ln E}=0.0068-0.0011 * \ln A_{0}$.

Meanwhile, we assume that the marginal effect of welfare use on the cognitive achievement production function is heterogeneous on the intercept but homogeneous on the interaction terms (inputs interacted with innate ability, $\ln A_{0}$ ). ${ }^{33}$ The welfare effects of Type I and Type II mothers on children's attainment are hence given by $\frac{\partial \ln O}{\partial \ln W_{h}}=$ $0.0797-0.1770 * \ln A_{0}$ and $\frac{\partial \ln O}{\partial \ln W_{l}}=0.0609-0.1770 * \ln A_{0}$, respectively. Note that a mother's type of welfare use in the utility function and the production function of the child's cognitive attainment is linked. Ex-ante, a so-called high welfare stigma mother (higher $\alpha_{4}$ ) is not necessarily associated with a better child rearing technology (higher $\gamma_{3}$ ). However, the data suggests that this is indeed the case.

\footnotetext{
${ }^{33} \mathrm{We}$ have estimated a version allowing heterogeneity on the interaction term as well. However, the difference is small. We drop the term for simplicity.
} 
Our estimates indicate that the observed innate ability $\left(\ln A_{0}\right)$ ranges from 0.095577 to 0.484886. Figure 1(a) and Figure 1(b) draw the marginal effects of work and welfare use, respectively, against the distribution of $\ln A_{0}$. Figure 1(a) indicates that a mother's work improves her child's math test score, but the effect declines with the child's innate ability. Everything else being constant, the marginal change in attainment resulting from a one year increase in work ranges from 0.45 percent at the lowest innate ability to 0.41 percent at the highest, with the median effect (the marked dashed line) at about 0.426 percent. The highest, lowest and median marginal effects translate to the standardized test scores of $.419, .382$ and .396 points, respectively. This means that returns for time with a child are higher if a child has high observed innate ability.

Figure 1(b) lists the marginal effects of welfare use for the two types of mothers against all possible ranges of the observed innate ability. Table 7 shows that there are 64 percent Type I mothers (mothers with $\alpha_{4 H}$ and corresponding $\gamma_{3 H}$ ), and that the remaining 36 percent are considered as Type II mothers (with $\alpha_{4 L}$ and $\gamma_{3 L}$ ). For a Type I mother, the net marginal effect of welfare use on her child ranges from 6.3 percent to -0.62 percent points, with a median of 2.2 percent. This effect is quite substantial, as it translates to a 2.07 points increase in the mean PIAT-Math test score. As a result, a Type I mother, although with higher disutility, can potentially benefit her child greatly from using welfare, save for children with the highest innate ability levels for whom welfare has a detrimental effect.

On the contrary, for about half of the children with Type II mothers, the net effect of welfare use on the child's cognitive achievement is negative. The net effect of welfare use on this kind of child ranges from 4.5 percent to -2.41 percent log points per year, with an effect on median child 0.417 percent, which is about .387 points increase in the standardized test score. Recall that the coefficients of welfare use in the attainment production function, Equation (7), capture the benefits from in-kind transfer programs such as Medicaid, Head Start or subsidized child care. We would expect Medicaid to have universal benefit for all participants. However, Head Start or subsidized child care 
may benefit a child with lower observed innate ability more compared to the higher innate ability counterpart. Furthermore, if there is a negative role model effect, the benefits of these programs may not be enough for high ability children to overcome the detrimental effect of a negative role model.

Chyi and Ozturk (2012) estimate a similar attainment production function as Equation (7) using a correction function approach. In that study, they find that the marginal effects of an additional year of employment and welfare use for a child with median level of innate ability are at $1.44 \%$ (1.34 points) and $.649 \%$ (.604 points), respectively. ${ }^{34}$ Both current estimates from the structural model have the same signs as the reduced-form estimates. However, both estimates are smaller than the estimates derived from Chyi and Ozturk (2012). The structural estimates of the marginal effects of employment is .397 point, whereas the marginal effects of welfare use are 2.06 and .387 points for type I and II mothers, respectively. As a result, the reduced form estimation gives a higher employment effect but a lower welfare use effect. After closely examining the regressors, we realize that in the structural model, two regressors: a mother's prior welfare and prior work experiences (from eight quarters prior her child's birth) are not included in the reduced form version. As a result, the structural model estimates can be seen as partial effect conditional on specific levels of prior-birth decisions, whereas in the reduced form version, the effects of a mother's decisions incorporate not only the above-mentioned effect, but also the effect from the positive correlation between pre- and post-decisions. ${ }^{35}$

This estimated positive employment effect, however small in magnitude, is significantly different from Bernal (2008) and Bernal and Keane (2010 and 2011), who find that a mother's employment is detrimental to a child's cognitive achievement. For example,

\footnotetext{
${ }^{34}$ In Chyi and Ozturk (2012), the dependent variable, PIAT Math Standardized test score, is not in logarithm. We convert these marginal effects in points to percentages by dividing them with the median test score, which is 93.1 in the sample.

${ }^{35}$ The effect of inclusion of prior decisions in the outcome function can be seen from the below illustration. Suppose the following (simplified) outcome equation is the "true" model:

$$
\begin{aligned}
\ln O_{t} & =\beta_{0}+X_{t}^{\prime} \beta+\beta_{1} \text { prior work }+\beta_{2} \text { prior welfare } \\
& +\beta_{3} E_{t}+\beta_{4} W_{t}+\beta_{5} \text { prior work } \times E_{t}+\beta_{5} \text { prior welfare } \times W_{t} .
\end{aligned}
$$
}


Bernal (2008) finds that the quarterly marginal effect of employment ranges from 0.33 percent to -0.7 percent, with a mean of -0.25 percent. After a closer look at their sample, we find several potential sources of sampling variation between their studies and ours that may explain the different estimates. Appendix A.2 provides a detailed comparison between our empirical strategies and an explanation of the variation of our results. Here we summarize the key findings. First, Bernal (2008) focuses on a population of betterskilled mothers, who potentially may have different child rearing technology and children of much higher innate abilities. Second, Bernal and Keane (2010 and 2011) study the effect of child care focusing on a group of single mothers that also includes better-educated mothers. Finally, since NLSY79 does not provide detailed child care information, they use employment as a proxy. We find that about 20 percent of our sample reported using child care in the first three years but no employment. However, such cases are defined as having worked in Bernal and Keane (2010 and 2011). Using a reduced form approach listed in Appendix A.2, we find that such variations in the definition of employment explains a significant part of the variation between our results.

In this case,

$$
\begin{aligned}
& \left.\frac{\partial \ln O_{t}}{\partial E_{t}}\right|_{\text {prior exp. }}=\beta_{3}+\beta_{5} \text { prior exp. } \\
& \left.\frac{\partial \ln O_{t}}{\partial W_{t}}\right|_{\text {prior exp. }}=\beta_{4}+\beta_{5} \text { prior exp. }
\end{aligned}
$$

where "prior exp." indicates both prior work and welfare use experiences.

On the other hand, if we do not control prior experiences, as is the case in Chyi and Ozturk (2012), the marginal effects of the mother's decisions become:

$$
\begin{aligned}
& \frac{\partial \ln O_{t}}{\partial E_{t}}=\left.\frac{\partial \ln O_{t}}{\partial E_{t}}\right|_{\text {prior exp. }}+\left(\beta_{1}+\beta_{5} E_{t}\right) \frac{\partial \text { prior work }}{\partial E_{t}}+\left(\beta_{2}+\beta_{5} W_{t}\right) \frac{\partial \text { prior welfare }}{\partial E_{t}}, \\
& \frac{\partial \ln O_{t}}{\partial W_{t}}=\left.\frac{\partial \ln O_{t}}{\partial W_{t}}\right|_{\text {prior exp. }}+\left(\beta_{1}+\beta_{5} E_{t}\right) \frac{\partial \text { prior work }}{\partial W_{t}}+\left(\beta_{2}+\beta_{5} W_{t}\right) \frac{\partial \text { prior welfare }}{\partial W_{t}}
\end{aligned}
$$

Given the highly positive correlations between pre- and post-birth same decisions, and the highly negative correlations between pre- and post-birth cross decisions, it is easy to see that positive $\beta_{1}$ and negative $\beta_{2}$ and $\beta_{5}$ can result in the reduced form version capturing a much higher employment effect while a much smaller welfare use effect. Also see Appendix A.2 for a further discussion. 


\subsection{Model Fit}

Figure 2(a) and Figure 2(b) provide support for how well the model fits the data. Overall, we fit the participation rates for welfare and work nicely. We predict more than 96 percent of mothers' welfare behavior and 93 percent of work choices successfully. However, our

estimation of welfare misses about 4 percentage points in the first period (an underestimation) and in the last period (an overestimation). At the same time, our prediction for work is understated slightly in the middle three periods ( 5 percentage points on average).

\subsection{Understanding Unobserved Heterogeneity}

Table 7 collects all parameters that are related to different types of mothers. Figure 3 draws the annual means of welfare use and work patterns for mothers of different types. As can be expected, they have noticeable differences in terms of welfare use, as mothers with higher welfare stigma (Type I mothers) use slightly less welfare since their children's birth. On the other hand, there is no significant difference in employment patterns between mothers who have different degrees of welfare stigma. As discussed before, we assume the distaste of work in the utility function to be the same between the two types of mothers. The difference in work patterns is hence generated initially, through variation in income from their different welfare use patterns and later, through variation in wage offers through different accumulated work experiences.

The difference in children's annual attainment $\left(\ln A_{t}\right)$ between the two types of mothers is much larger, as can be seen in Figure 3. Through their different rearing technology, $\gamma_{5}$, even similar employment and welfare patterns allowed Type I mothers to better utilize the benefits brought by participating in welfare programs to educate their children. As a result, better rearing technology of Type I mothers becomes the dominant effect that their children will have a much higher attainment than their counterparts who have similar observed innate ability.

The fact that we have more Type I mothers is encouraging. First, since the effects 
of employment is mostly positive, policies that are pro-employment will be beneficial to most children's attainment. On the other hand, policies that curb welfare use will not affect children born to Type I mothers ex-post, as their mothers do not use welfare much anyway. As for children born to Type II mothers, reducing welfare use actually is beneficial for at least half of them, given that the marginal effect of welfare use is negative for children with more than the median level of observed innate ability.

Based on this discussion, we see the benefit of allowing mothers to have different tastes in using welfare and then linking this taste with mothers' technologies for rearing their children. By estimating the proportion of the two types of mothers in the data and the different technologies of utilizing a welfare benefit, we are able to disentangle further the potential effects of welfare reform initiatives on children's attainment.

\section{Policy Analysis}

Using the estimated parameters, we simulate the effects of three policy changes. These policy changes gauge mothers' behavioral responses facing (i) a welfare time limit and work requirement, (ii) a relief of welfare tax on labor income and (iii) a policy that is similar to maternity leave. In each policy exercise, we look at the changes in work and welfare participation and analyze how achievement measures differ for children of women with different work and welfare choices.

\subsection{Time Limit on Welfare and Work Requirement}

According to the new TANF rules, the longest time one can be on welfare without working is two years, and the cumulative welfare use cannot exceed five years. We simulate this policy by setting benefits to zero if cumulative welfare use exceeds two years and no 
work is chosen. ${ }^{36}$ Figures 4(a) and 4(b) document the behavioral responses for an average mother whose observed covariates are at the sample mean. As can be seen from the Figure 4(b), welfare choice decreases by about one percentage point in the first two periods. After that, welfare participation decreases sharply by about 13 percentage points. Meanwhile, the increase in work participation is also significant (Figure 4(a)). The employment rate goes up by about 9 percentage points in the first two periods. In the last three periods, this increase reaches more than 30 percentage points.

These results indicate that the combination of a welfare time limit and work requirement has a sizable effect on mothers' behaviors. The explanation is straight-forward. Considering a typical mother who currently gets all of her income from welfare, according to the new TANF rules, she will no longer be able to receive a welfare benefit after the first two years. Thus, she will choose to work to make up for the lost income, which is exactly the reason for the sharp increase in employment rates after two periods. Note that in our model, one can find employment so long as one wants to. Since we do not model the job matching difficulty and a mother's searching intensity, the insurance aspect of welfare use is not factored into our model. As a result, welfare use does not decline by as much as what we have seen in real life.

Our results are in line with other studies on the effects of welfare reform on mothers' behaviors. For example, Fang and Keane (2004) also focus on single mothers and find that both work requirements and welfare time limits, after controlling for other factors such as the 1993 EITC expansion and the unprecedented economic expansion in the 1990s, can largely account for the decrease in the welfare participation rate and the increase in the work participation rate. Furthermore, Grogger and Michalopoulos (2003) argue that the effects of welfare time limits may be largest on mothers who have younger children, since they value the insurance purpose of the welfare program more.

Finally, this policy increases the mean of simulated test scores by about 1.8 percent (or a 1.68 points increase in test score. See Figure 4(c)). Even though our model is naive

\footnotetext{
${ }^{36}$ Since we only model the first five years of a child's live, it is not possible for us to impose the five-year time limit.
} 
in the sense that we have not taken into account the difficulty of finding a job, we find that at least at the mean level, the negative impact of welfare reduction on achievement is dominated by the positive impact of increasing work on achievement. Our prediction is also supported by Miller and Zhang (2009), who pursue a difference-in-difference strategy using fourth and eighth graders from both pre- and post- welfare reform years. Their findings complement ours by showing the persistence of early gains up to the eighth grade level. Both our paper and Miller and Zhang (2009) indicate that children with lower innate ability gain more from welfare reform. This implies that the differential returns to employment and welfare use by innate ability also persist in the long run.

\subsection{Eliminate Welfare Tax on Labor Income}

In this experiment, we relax the relationship between the welfare use decision and the work decision. We simulate this policy by assuming that work income would not reduce the benefit from welfare use (in other words, we set $b_{8}+\sum_{s} b_{9 s} D_{s}=0$ ).

With this policy change, work would be more attractive to mothers who are on welfare because now working income will not have a negative effect on the welfare benefit. The increase in work decisions is about 6.5 percentage points in the first period. Then it increases gradually to 12 percentage points in the last period. However, this policy change only has a slightly positive effect on welfare use (see Figures 5(a) and 5(b)). Still, the impact of this policy reform on children's ability achievement is implicit. The increase of mean log achievement is only about 0.46 percent (or .43 point in standardized test score. See Figure 5(c) $)$, which is far smaller than the effect of a combination of welfare time limit and work requirement as proposed in the previous experiment.

As a result, if the policy goal is to promote work, reducing welfare tax on labor income can be a valid alternative in the sense that it sharply increases employment. Furthermore, it slightly increases the attainment of children whose mothers are on welfare. 


\subsection{Maternity Leave Policy}

In this experiment, we analyze the impact of a maternity leave policy (beyond the 4 weeks that is allowed in US now) for which there is no wage penalty for the time out of the labor market after giving birth. This policy change is brought about by setting the wage depreciation rate of the first year to zero. ${ }^{37}$

This policy change would have no effect on those mothers who do not have work experiences before giving birth. Thus, we focus on the proportion of the sample who worked before giving birth (only $42 \%$ of the whole sample). With this policy change, the employment rate decreases by about nine percentage points in the first year. After the first period, the growth in employment appears to follow a similar trend as those in the real data. As a result, this policy decreases the initial employment in the first year after birth for those people who have prior work experiences, and the employment rate for this group fails to catch up in the later periods as well. On the contrary, the increase in welfare use is minuscule in the first two periods. Then it increases sharply from three percentage points to ten percentage points. (See Figures 6(a) and 6(b) )

Because the maternity leave policy decreases the wage depreciation cost of leaving a job, fewer mothers would choose to work in the first period after giving birth. This reduction would continue for the remaining periods because less benefit is received from the working experience. At the same time, these mothers would rather choose welfare to make up for the loss of their income. However, this policy reform has little impact on children's achievement. The decrease of mean log achievement is only about 0.68 percent. (See Figure 6(c)),

The type of policy change we have simulated, although new in the U.S., is still much lower than in other developed countries. Most OECD countries offer up to 14 months maternity leave, and Canada recently increased its maternity leave from 6 months to a full year. When Canada changed its maternity leave policy, the percentage of mothers who

\footnotetext{
${ }^{37}$ In the second year wage equation $\left(\ln w_{2}\right.$ in Equation $(5)$ ), we also set the work premium terms for the second year after child-birth (corresponding to $\phi_{9}$ and $\phi_{10}$ ) equal to the work premium in the first year after child-birth.
} 
went back to work within the first nine months declined significantly, from 53 percent to about 33 percent (Baker and Milligan, 2008).

Note that this policy experiment only applies to about $40 \%$ of our sample mothers who have prior-birth work experiences. As a result, the average effect on the whole population is even smaller. Our finding of a decrease in labor force participation is in line with the findings of Baker and Milligan (2008), who find that when Canada changed its maternity leave policy, the percentage of mothers who went back to work within the first nine months declined significantly, from 53 percent to about 33 percent. Furthermore, Han, Ruhm, Waldfogel and Washbrook (2009) also find that within nine months of leaving work after child birth, about 60 percent of all women go back to work. This is especially high among Black, new mothers who are the majority of our welfare users. They further indicate that women who are non-college graduates, young and single are the individuals who are most likely to go back to work within two months of birth, whereas mothers who are older, married, and at least college graduates are the least likely, because they are likely to have savings to draw upon and access to maternity leave through their workplaces.

\section{Conclusion}

Even though our data and model are restricted for simplicity, our results reveal significant and interesting policy effects. We allow welfare to affect cognitive development through multiple channels. Cumulative income input captures the income effect of welfare use. A work experience variable captures the effects of time spent with the child by substituting welfare for work. Once these two channels are controlled for, a welfare-use variable captures mainly the benefits from nonpecuniary means-tested transfers programs that are linked with the welfare program, such as Medicaid. The effect of welfare use is identified not only by a comparison between children with and without childhood welfare experiences, but also by comparing children who have different levels of exposure to the welfare 
program during the first five years after birth. Also, we include parameters of the AFDC benefit determination rule for each U.S. state and a measure of county-level labor market tightness for added exogenous variation for identification.

We use the first observed PIAT-math scores from the Children of NLSY79 as a measure of attainment. We find that a mother's employment benefits a child's cognitive development, especially if the child has low innate ability. These results are significantly different from the literature which documents negative cognitive achievement responses to a mother's employment. We find work to be non-detrimental to test scores, a widely used measure of cognitive development in the literature. This positive impact may be capturing the effect that working mothers provide a positive role model for their children to follow.

We link the mothers' different tastes for welfare use with their different technologies in rearing their children. For Type I mothers, who suffer more stigma in welfare use, welfare participation has a positive effect on a child's achievement because they can better utilize benefits brought from the welfare program. However, for children with Type II mothers, one extra year on welfare reduces the mean test score if their innate ability is at an above average level. The coefficients of welfare use in our model capture the benefits from in-kind transfer programs, such Head Start or subsidized child care. These two may be benefiting low ability children more than high ability children. However, the benefits from these programs may not be enough for high ability children to overcome the influence of a negative role model if Type II mothers utilize these benefits with bad technology to rear their children.

By estimating the structural parameters, we are also able to conduct counterfactual policy analysis to investigate the effects of policy changes. We find that the work requirement and welfare limit introduced by welfare reform simultaneously reduces a single mother's use of welfare and increases her work choice possibility. The combination of a time limit on welfare and a work requirement increases test scores by about 1.8 percent. One other paper, Miller and Zhang (2009), documents positive effects of welfare reform 
on the cognitive measures of welfare children.

We also looked at two policies that are not currently implemented but maybe of interest: a maternal leave policy and a relief of welfare tax on labor income. We find that the introduction of a maternal leave policy increases welfare participation by about 6 percentage points. While it increases the employment rate about 9 percentage points in the first period, this effect decreases gradually thereafter. Consequently simulated test scores decrease by 0.68 percent. A policy of exempting labor income for welfare tax, on the contrary, increases test scores by 0.42 percent. This policy increases employment by 10 percentage points on the average but only has limited positive effect on welfare use.

\section{References}

[1] Baker, Michael, J. Gruber and K. Milligan, 2008, "Universal Child Care, Maternal Labor Supply, and Family Well-Being." Journal of Political Economy, vol. 116(4), pp. 709-745.

[2] Baker, Michael and K. Milligan, 2008, "Maternal employment, breastfeeding, and health: Evidence from maternity leave mandates." Journal of Health Economics, vol. 27(4), pp. 871-887.

[3] Bedard, K., and E. Dhuey, 2006, "Older Children Outperform Younger Children in the Same Entry Cohort." Quarterly Journal of Economics, vol. 121(4), pp. 14371472 .

[4] Bernal, R., 2008, “The Effect of Maternal Employment and Child Care on Children's Cognitive Development.” International Economic Review, vol. 49, pp. 1173-1209.

[5] Bernal, R., and M. Keane, 2010, "Quasi-Structural Estimation of a Model of Childcare Choices and Child Cognitive Ability Production." Journal of Econometrics, vol. 156, pp. 164-189.

[6] Bernal, R., and M. Keane, 2011, "Child Care Choices and Children's Cognitive Achievement: The Case of Single Mothers." Journal of Labor Economics, forthcoming.

[7] Ben-Porath, Yoram, 1967, "The Production of Human Capital and the Lifecycle of Earnings.” Journal of Political Economy, Vol. 75, pp. 352-365.

[8] Blau, Francine D and Adam J. Grossberg, 1992, "Maternal Labor Supply and Children's Cognitive Development." The Review of Economics and Statistics, vol. 74(3), pp. 474-81. 
[9] Brooks-Gunn, J., Han, W.J., Waldfogel, J., 2002, "Maternal Employment and Child Cognitive Outcomes in the First Three Years of Life: The NICHD Study of Early Child Care." Child Development, vol. 73(4), pp. 1052-1072.

[10] Cascio, E., 2009, "Maternal Labor Supply and the Introduction of Kindergartens into American Public Schools.” Journal of Human Resources, Vol. 44, pp. 140-170.

[11] Cascio, E., and D. W. Schanzenbach, 2007, "First in Class? Age and the Education Production Function.” NBER Working Paper 13663.

[12] Chyi, H., and O. Ozturk, 2012, "The Effects of Single Mothers' Welfare Use and Employment Decisions on Children's Cognitive Development." Economic Inquiry, forthcoming.

[13] Claessens, A., Duncan, G., and Engel, M. 2009, "Kindergarten skills and fifth-grade achievement: Evidence from the ECLS-K." Economics of Education Review, vol. 28, pp. 415-427.

[14] Currie, J., 1998, "The Effect of Welfare on Child Outcomes: What We Know and What We Need to Know.” JCPR Working Papers 26, 1998.

[15] Currie, J. and Hotz, V. Joseph, 2004. "Accidents will happen?: Unintentional childhood injuries and the effects of child care regulations," Journal of Health Economics, vol. 23(1), pp. 25-59.

[16] Currie, J. and D. Thomas, 1995. "Does Head Start Make a Difference?" American Economic Review, vol. 85(3), pp. 341-64.

[17] Dahl, G., and L. Lochner, 2005, “The Impact of Family Income on Child Achievement.” NBER Working Paper 11270.

[18] Duncan, G. J., and J. Brooks-Gunn, 1997, Consequences of Growing up Poor. New York: Russell Sage Foundation.

[19] Duncan G., Magnuson K., and Ludwig, J., 2004,“The Endogeneity Problem in Developmental Studies.” Research in Human Development, I(1\&2), pp. 59-80.

[20] Duncan, G, Dowsett, C., Claessens, A., Magnuson, K., Huston, A., Klebanov, P., Pagani, L., et al. (2007). "School Readiness and Later Achievement." Developmental Psychology, 43, 1428-1446.

[21] Fang, Hanming and Michael P. Keane, 2004, "Assessing the Impact of Welfare Reform on Single Mothers." Brookings Papers on Economic Activity, vol. 35(1), pp. $1-116$.

[22] Grogger, J., and Michalopoulos, C., 2003, "Welfare Dynamics under Time Limits." Journal of Political Economics, vol. 111(3), 530-554.

[23] Han, Wen-Jui, Ruhm C., Waldfogel J., and Washbrook E., 2009, "Public Policies and Women's Employment after Childbearing." NBER Working Papers 14660.

[24] Haveman, R. and Wolfe, B., 1995, "The Determinants of Children's Attainments." Journal of Economic Literature, vol. 33 , pp. 1829-78. 
[25] Keane, M. and Moffitt, R., 1998, "A Structural Model of Multiple Welfare Program Participation and Labor Supply." International Economic Review, vol. 39(3), pp. 553-89.

[26] Keane, M. and Wolpin, K., 2002, "Estimating Welfare Effects Consistent With Forward-Looking Behavior: Part I: Lessons From A Simulation Exercise.” Journal of Human Resources, vol. 37(3), pp. 570-99.

[27] Miller, Amalia and Lei Zhang, 2009, "The Effects of Welfare Reform on the Academic Performance of Children in Low-Income Households." Journal of Policy Analysis and Management, vol. 28(4), pp. 577-599.

[28] Moffitt, 1983, “An Economic Model of Welfare Stigma." Amercian Economic Review, vol. 73(5), pp. 1023-1035.

[29] Moffitt, 2002, "Economic Effects of Means-Tested Transfers in the U.S." NBER Working Papers 8730.

[30] Morrill, Melinda Sandler, 2009, "The Effects of Maternal Employment on the Health of School-Age Children." unpublished manuscript.

[31] Todd, Petra and Kenneth I. Wolpin, 2003, "On the Specification and Estimation of the Production Function for Cognitive Achievement," The Economic Journal, vol. 113(485), pp. F3-33.

[32] Wood, R. G. and A. Rangarajan, 2003, "What's Happening to TANF Leavers Who Are Not Employed,’ Issue Brief, October 2003 (6), Mathematica Policy Research, Inc. 


\section{Tables and Graphs}

Table 1: Sample Descriptives - Means

\begin{tabular}{|c|c|c|c|}
\hline Mother's Decisions & & Mother's Characteristics & \\
\hline Welfare participation & $\begin{array}{c}0.794 \\
(0.404)\end{array}$ & Age at Birth & $\begin{array}{l}25.5 \\
(4.4)\end{array}$ \\
\hline $\begin{array}{c}\text { Annual Employment } \\
\text { Part-Time }\end{array}$ & 128 & Years of Education & $\begin{array}{l}10.9 \\
(16)\end{array}$ \\
\hline $\begin{array}{c}\text { (500-1499 hours) } \\
\text { Full-Time }\end{array}$ & $\begin{array}{c}(0.335) \\
0.186\end{array}$ & Number of Children & $\begin{array}{c}2.4 \\
(1.3)\end{array}$ \\
\hline $\begin{array}{l}(>=1500 \text { hours }) \\
\text { Hours of Work }\end{array}$ & $\begin{array}{c}(0.389) \\
1605\end{array}$ & $\begin{array}{l}\text { Annual Labor } \\
\text { Income* }\end{array}$ & $\begin{array}{l}10,737.2 \\
(9,070.4)\end{array}$ \\
\hline ( Conditional on work) & $(626)$ & $\begin{array}{l}\text { Annual Other } \\
\text { Income* }\end{array}$ & $\begin{array}{c}6,063.0 \\
(33,938.9)\end{array}$ \\
\hline$\frac{\text { Child's Characteristics }}{\text { Female/Male }}$ & $0.48 / 0.52$ & AFQT & $\begin{array}{c}14.2 \\
(14.0)\end{array}$ \\
\hline Black/Others & $0.74 / 0.26$ & County Characteristics & \\
\hline Birth Weight(Ounces) & $\begin{array}{l}110.7 \\
(22.9)\end{array}$ & Unemployment Rate & $\begin{array}{l}7.8 \\
(3.2)\end{array}$ \\
\hline Age Taking Test (Quarters) & $\begin{array}{l}25.3 \\
(4.8)\end{array}$ & Service Industry & $\begin{array}{c}0.16 \\
(0.04)\end{array}$ \\
\hline PIAT-Math Score & $\begin{array}{c}93.1 \\
(13.4)\end{array}$ & Medium Income & $\begin{array}{l}23,967.1 \\
(6,228.3)\end{array}$ \\
\hline Child-Years & 2,820 & & \\
\hline Children & 564 & & \\
\hline Mothers & 392 & & \\
\hline
\end{tabular}

- Standard errors are in parentheses.

- Population weighted to reflect the 1979 national population of low-skilled single mothers.

* In 2000 dollars deflated by PCED-nondurable.

Table 2: Mother's Employment and Welfare Use by Child's

Age

\begin{tabular}{lcccc}
\hline $\begin{array}{l}\text { Child's } \\
\text { Age }\end{array}$ & $\begin{array}{c}\text { Welfare } \\
\text { Use }\end{array}$ & $\begin{array}{c}\text { Part-Time } \\
(500-1499 \text { Hours })\end{array}$ & $\begin{array}{c}\text { Full-Time } \\
(\geq 1500 \text { Hours })\end{array}$ & $\begin{array}{c}\text { Hours } \\
\text { of Work }^{\dagger}\end{array}$ \\
\hline-2 & 0.54 & 0.16 & 0.18 & 1510 \\
& $(0.50)$ & $(0.36)$ & $(0.39)$ & $(628)$ \\
-1 & 0.67 & 0.15 & 0.17 & 1519 \\
& $(0.47)$ & $(0.36)$ & $(0.37)$ & $(657)$ \\
1 & 0.81 & 0.11 & 0.12 & 1463 \\
& $(0.39)$ & $(0.31)$ & $(0.32)$ & $(538)$ \\
2 & 0.79 & 0.13 & 0.17 & 1532 \\
& $(0.41)$ & $(0.34)$ & $(0.38)$ & $(600)$ \\
3 & 0.81 & 0.12 & 0.19 & 1625 \\
& $(0.39)$ & $(0.32)$ & $(0.39)$ & $(633)$ \\
4 & 0.80 & 0.13 & 0.22 & 1692 \\
& $(0.40)$ & $(0.34)$ & $(0.42)$ & $(684)$ \\
5 & 0.76 & 0.15 & 0.22 & 1651 \\
& $(0.43)$ & $(0.35)$ & $(0.42)$ & $(618)$ \\
\hline
\end{tabular}

- Standard errors are in parentheses.

${ }^{\dagger}$ Conditional on work. 
Table 3: Detailed Descriptive Statistics of Test Scores by Quartiles of Demographic Characteristics

\begin{tabular}{|c|c|c|c|c|c|}
\hline & \multicolumn{4}{|c|}{ Quartile } & \\
\hline & 1 st & 2nd & $3 \mathrm{rd}$ & 4th & \\
\hline PIAT-Math Score & $\begin{array}{l}75.60 \\
(5.56)\end{array}$ & $\begin{array}{l}89.40 \\
(2.67)\end{array}$ & $\begin{array}{l}98.40 \\
(2.75)\end{array}$ & $\begin{array}{l}111.02 \\
(6.43)\end{array}$ & \\
\hline \multicolumn{6}{|l|}{ Mother's Characteristics } \\
\hline $\begin{array}{l}\text { Real Hourly Wages }^{\dagger} \\
\text { Mean Standard Test Scores } \\
\text { (Standard Deviation of Scores) }\end{array}$ & $\begin{array}{c}1.1 \\
94.8 \\
(13.7)\end{array}$ & $\begin{array}{c}2.6 \\
92.4 \\
(14.8)\end{array}$ & $\begin{array}{c}4.8 \\
95.8 \\
(12.5)\end{array}$ & $\begin{array}{c}10.6 \\
96.7 \\
(12.7)\end{array}$ & \\
\hline Average Labor Income ${ }^{\dagger}$ & $\begin{array}{c}181.6 \\
94.8 \\
(13.4)\end{array}$ & $\begin{array}{l}1010.9 \\
97.3 \\
(13.6)\end{array}$ & $\begin{array}{l}3598.1 \\
93.2 \\
(13.2)\end{array}$ & $\begin{array}{c}11,823.2 \\
96.2 \\
(12.2)\end{array}$ & \\
\hline Average Other Income & $\begin{array}{c}479.0 \\
94.0 \\
(14.50)\end{array}$ & $\begin{array}{c}1919.4 \\
93.5 \\
(13.90)\end{array}$ & $\begin{array}{l}4126.5 \\
93.6 \\
(12.90)\end{array}$ & $\begin{array}{l}19,805.8 \\
94.8 \\
(12.70)\end{array}$ & \\
\hline AFQT Score & $\begin{array}{c}3.0 \\
90.2 \\
(13.2)\end{array}$ & $\begin{array}{c}7.8 \\
92.3 \\
(12.8)\end{array}$ & $\begin{array}{c}14.0 \\
94.1 \\
(12.5)\end{array}$ & $\begin{array}{c}34.9 \\
96.7 \\
(14.3)\end{array}$ & \\
\hline Education & $\begin{array}{c}<12 \\
91.4 \\
(13.60)\end{array}$ & $\begin{array}{c}=12 \\
94.7 \\
(13.30)\end{array}$ & & & \\
\hline Age at Birth & $\begin{array}{c}21.1 \\
93.9 \\
(13.20)\end{array}$ & $\begin{array}{c}25.0 \\
93.5 \\
(13.40)\end{array}$ & $\begin{array}{c}28.4 \\
92.6 \\
(13.20)\end{array}$ & $\begin{array}{c}33.7 \\
92.0 \\
(14.00)\end{array}$ & \\
\hline \multicolumn{6}{|l|}{ Child's Characteristics } \\
\hline Race & $\begin{array}{c}\text { Black } \\
73.8 \\
93.6 \\
(11.89)\end{array}$ & $\begin{array}{c}\text { Hispanic } \\
12.9 \\
92.2 \\
(13.59)\end{array}$ & $\begin{array}{c}\text { Other } \\
13.3 \\
97.8 \\
(13.24)\end{array}$ & & \\
\hline Gender & $\begin{array}{l}\text { Male } \\
92.6 \\
(13.80)\end{array}$ & $\begin{array}{l}\text { Female } \\
93.6 \\
(13.03)\end{array}$ & & & \\
\hline Number of Siblings & $\begin{array}{c}1 \\
0 \\
95.7 \\
(13.62)\end{array}$ & $\begin{array}{c}2 \\
1 \\
95.3 \\
(13.73)\end{array}$ & $\begin{array}{c}3 \\
2 \\
93.0 \\
(12.53)\end{array}$ & $\begin{array}{c}4 \\
3 \\
90.7 \\
(13.00)\end{array}$ & $\begin{array}{c}>3 \\
90.2 \\
(14.10)\end{array}$ \\
\hline $\begin{array}{l}\text { Age Taking Test } \\
\text { (Quarters) }\end{array}$ & $\begin{array}{c}21.2 \\
91.6 \\
(14.70)\end{array}$ & $\begin{array}{c}24.1 \\
94.6 \\
(12.70)\end{array}$ & $\begin{array}{c}26.4 \\
93.3 \\
(12.50)\end{array}$ & $\begin{array}{c}32.1 \\
92.5 \\
(13.50)\end{array}$ & \\
\hline \multicolumn{6}{|l|}{ County Characteristics } \\
\hline Unemployment Rate & $\begin{array}{c}4.7 \\
93.5 \\
(14.0)\end{array}$ & $\begin{array}{c}6.5 \\
93.2 \\
(13.6)\end{array}$ & $\begin{array}{c}8.3 \\
93.0 \\
(12.8)\end{array}$ & $\begin{array}{c}12.3 \\
92.7 \\
(13.4)\end{array}$ & \\
\hline Service Industry & $\begin{array}{c}0.09 \\
93.9 \\
(13.7)\end{array}$ & $\begin{array}{c}0.14 \\
92.4 \\
(13.0)\end{array}$ & $\begin{array}{c}0.18 \\
92.2 \\
(12.5)\end{array}$ & $\begin{array}{c}0.22 \\
94.0 \\
(14.4)\end{array}$ & \\
\hline Medium Income & $\begin{array}{c}15,433.50 \\
92.4 \\
(13.4)\end{array}$ & $\begin{array}{c}21,000.50 \\
94.1 \\
(14.0)\end{array}$ & $\begin{array}{c}25,317.30 \\
92.3 \\
(13.1)\end{array}$ & $\begin{array}{c}31,582.70 \\
93.7 \\
(13.1)\end{array}$ & \\
\hline
\end{tabular}

- Standard errors are in parentheses.

$\dagger$ Conditional on work. 
Table 4: Log-wage Estimates

\begin{tabular}{lc}
\hline Variables & Coefficient \\
\hline Time-Invariant & 0.0634 \\
Years of Schooling $\left(\phi_{1}\right)$ & $(0.0200)$ \\
& -0.0010 \\
Years of Schooling Squared $\left(\phi_{2}\right)$ & $(0.0010)$ \\
Race $\left(\phi_{3}\right)$ & -0.0030 \\
& $(0.0200)$ \\
Education $\left(\phi_{4}\right)$ & 0.0046 \\
& $(0.0010)$ \\
AFQT $\left(\phi_{5}\right)$ & 0.0011 \\
& $(0.0030)$ \\
Constant $\left(\phi_{6}\right)$ & 0.5155 \\
& $(0.1800)$ \\
Experience-Related & 0.0074 \\
Work Experience $\left(\phi_{7}\right)$ & $(0.0040)$ \\
& 0.0000 \\
Education*Experience $\left(\phi_{8}\right)$ & $(0.0000)$ \\
Part-Time Premium $\left(\phi_{9}\right)$ & 0.1171 \\
& $(0.0200)$ \\
Full-Time Premium $\left(\phi_{10}\right)$ & 0.2396 \\
& $(0.0002)$ \\
County Characteristics $\left(\phi_{11}\right)$ & -0.0007 \\
Unemployment Rate & $(0.0002)$ \\
& 0.0170 \\
Services Industry & $(0.0200)$ \\
& 0.0024 \\
Medium Income & $(0.002)$ \\
\hline &
\end{tabular}

- Standard errors are in parentheses. 
Table 5: Utility Parameters

\begin{tabular}{lc}
\hline Variables & Coefficient \\
\hline$\lambda$ & 0.518 \\
Consumption $\left(\alpha_{1}\right)$ & $0.0010)$ \\
& 0.798 \\
Taste for Work $\left(\alpha_{2}\right)$ & $(0.0003)$ \\
\hline Disutility from Work $\left(\overline{\alpha_{2}}\right)$ & -5.13 \\
& $(0.0020)$ \\
Mother's Education on Taste for Work $\left(\alpha_{21}\right)$ & -0.0050 \\
& $(0.0002)$ \\
Mother's Race on Taste for Work $\left(\alpha_{22}\right)$ & 0.0100 \\
Ability of the Child $\left(\alpha_{3}\right)$ & $(0.0002)$ \\
& 4.98 \\
Taste for Welfare $\left(\alpha_{4}\right)$ & $(0.021)$ \\
\hline Mother's Education on Taste for Welfare $\left(\alpha_{41}\right)$ & 0.0747 \\
& $(0.0002)$ \\
Mother's Race on Taste for Welfare $\left(\alpha_{42}\right)$ & -0.102 \\
& $(0.0002)$ \\
Disutility from Welfare Type I $\left(\overline{\alpha_{4 H}}\right)$ & -2.07 \\
Disutility from Welfare Type II $\left(\overline{\alpha_{4 L}}\right)$ & $(0.01)$ \\
& -0.649 \\
First Year on Welfare after Birth $\left(\alpha_{5}\right)$ & $(0.01)$ \\
& -3.61 \\
First Job after Birth $\left(\alpha_{6}\right)$ & $(0.003)$ \\
& -1.14 \\
Work in First Year after Birth $\left(\alpha_{7}\right)$ & $(0.02)$ \\
& -0.697 \\
& $(0.02)$ \\
\hline
\end{tabular}

- Standard errors are in parentheses. 
Table 6: Initial and Current Ability Parameters

\begin{tabular}{lc}
\hline Variables & Coefficient \\
\hline Initial Ability Parameters & 0.0009 \\
Birth Weight $\left(\gamma_{6}\right)$ & $(0.000)$ \\
Gender $\left(\gamma_{7}\right)$ & 0.0147 \\
Race $\left(\gamma_{8}\right)$ & $(0.001)$ \\
Mother Too Young Dummy $\left(\gamma_{9}\right)$ & -0.0308 \\
& $(0.000)$ \\
Mother Too Old Dummy $\left(\gamma_{10}\right)$ & -0.0371 \\
& $(0.029)$ \\
Education of Mother $\left(\gamma_{11}\right)$ & 0.0618 \\
& $(0.001)$ \\
AFQT $\left(\gamma_{12}\right)$ & 0.0317 \\
Prior Welfare $\left(\gamma_{13}\right)$ & $(0.001)$ \\
Prior Work $\left(\gamma_{14}\right)$ & 0.0014 \\
& $(0.001)$ \\
Current Ability Parameters & -0.0623 \\
Cumulative Income $\left(\gamma_{1}\right)$ & $(0.001)$ \\
& 0.0409 \\
Cumulative Work Experience $\left(\gamma_{2}\right)$ & $(0.001)$ \\
& \\
Cumulative Years on Welfare of Type I $\left(\gamma_{3 h}\right)$ & -0.0062 \\
Cumulative Years on Welfare of Type II $\left(\gamma_{3 l}\right)$ & $(0.050)$ \\
& 0.0100 \\
Cumulative Years on Welfare*Initial Ability $\left(\gamma_{4}\right)$ & $(0.000)$ \\
Cumulative Work Experience*Initial Ability $\left(\gamma_{5}\right)$ & 0.0781 \\
Outcome & $(0.005)$ \\
Age $\left(\gamma_{15}\right)$ & 0.0604 \\
Mean Test Score $\left(\mu_{0}\right)$ & -0.1753 \\
& $(0.050)$ \\
\hline & $(0.0043)$ \\
& \\
& 0.0873 \\
& $(0.002)$ \\
& 3.68 \\
& $(0.05)$ \\
\hline
\end{tabular}

- Standard errors are in parentheses. 
Table 7: Type-Related Parameters

\begin{tabular}{lc}
\hline Variables & Coefficient \\
\hline Type Proportions & \\
Type I Stigma from Benefit Use $\left(\pi_{h}\right)$ & 0.641 \\
Type II Stigma from Benefit Use $\left(\pi_{l}\right)$ & 0.359 \\
Welfare Stigma & \\
Disutility from Welfare Type I $\left(\overline{\alpha_{4 H}}\right)$ & -2.070 \\
& $(0.010)$ \\
Disutility from Welfare Type II $\left(\overline{\alpha_{4 L}}\right)$ & -0.649 \\
Rearing Technology & $(0.010)$ \\
Cumulative Years on Welfare of Type I $\left(\gamma_{3 h}\right)$ & 0.0781 \\
Cumulative Years on Welfare of Type II $\left(\gamma_{3 l}\right)$ & $(0.005)$ \\
& 0.0604 \\
& $(0.005)$ \\
\hline
\end{tabular}

- Standard errors are in parentheses. 
Figure 1: Effects of Mothers' Decisions on Ability Given Initial Ability

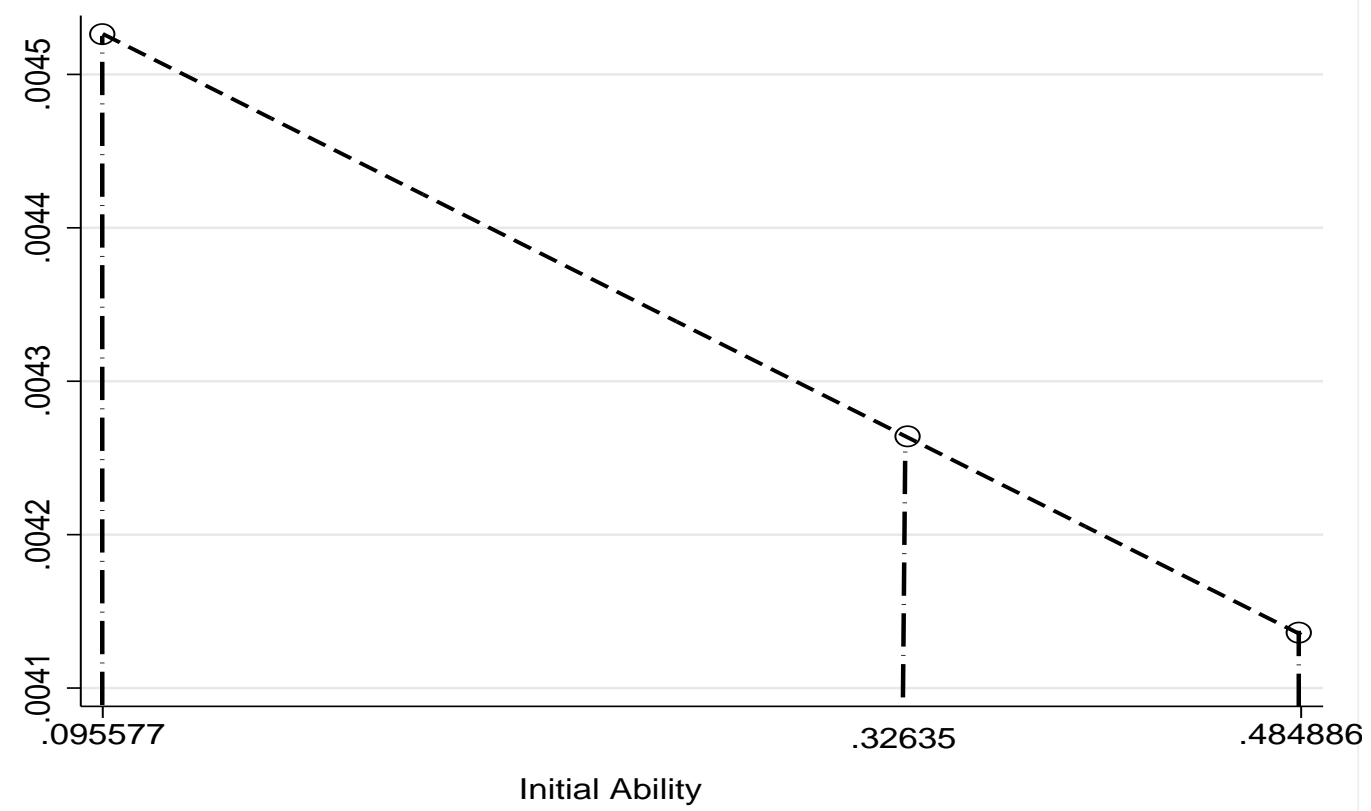

(a) Effect of work experience on ability for a given innate ability

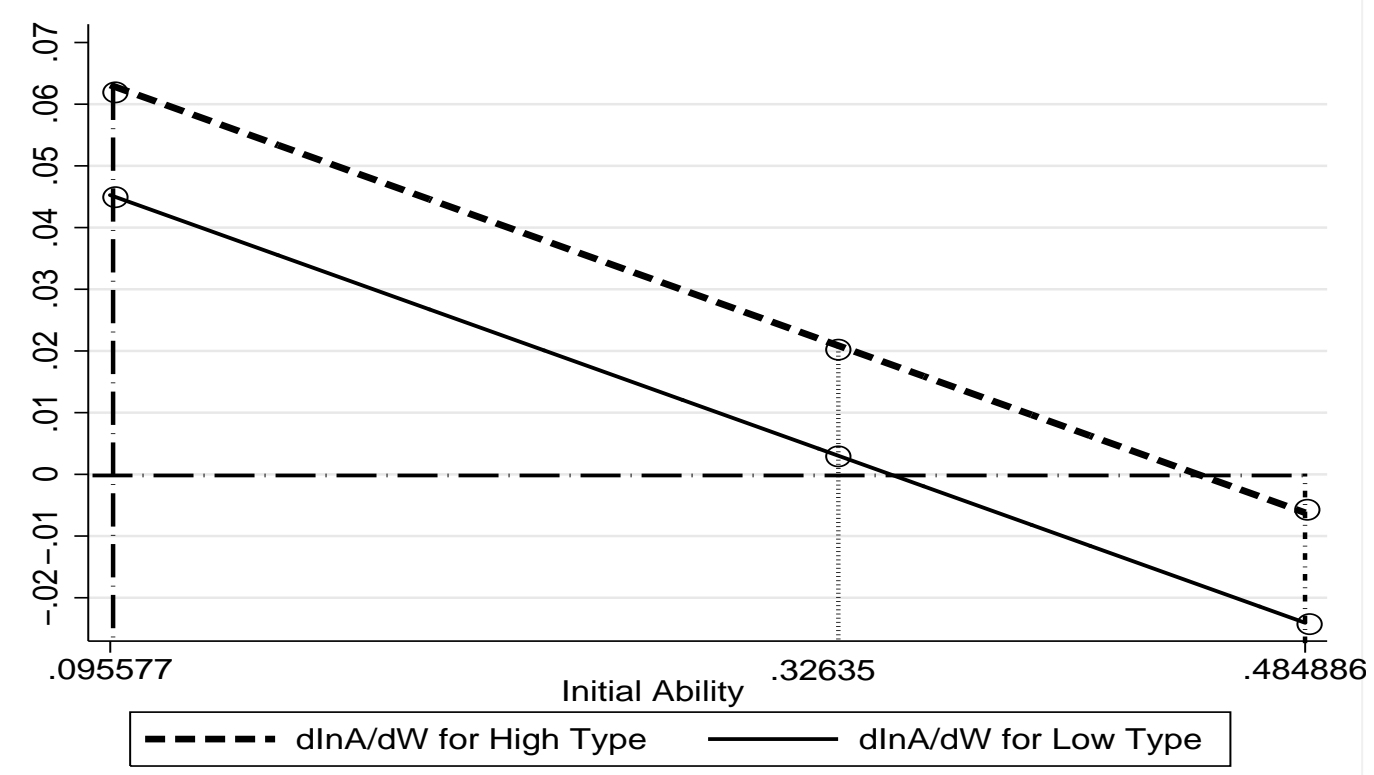

(b) Effect of welfare experience on ability for a given innate ability 
Figure 2: Model Fitness of Mothers' Decisions

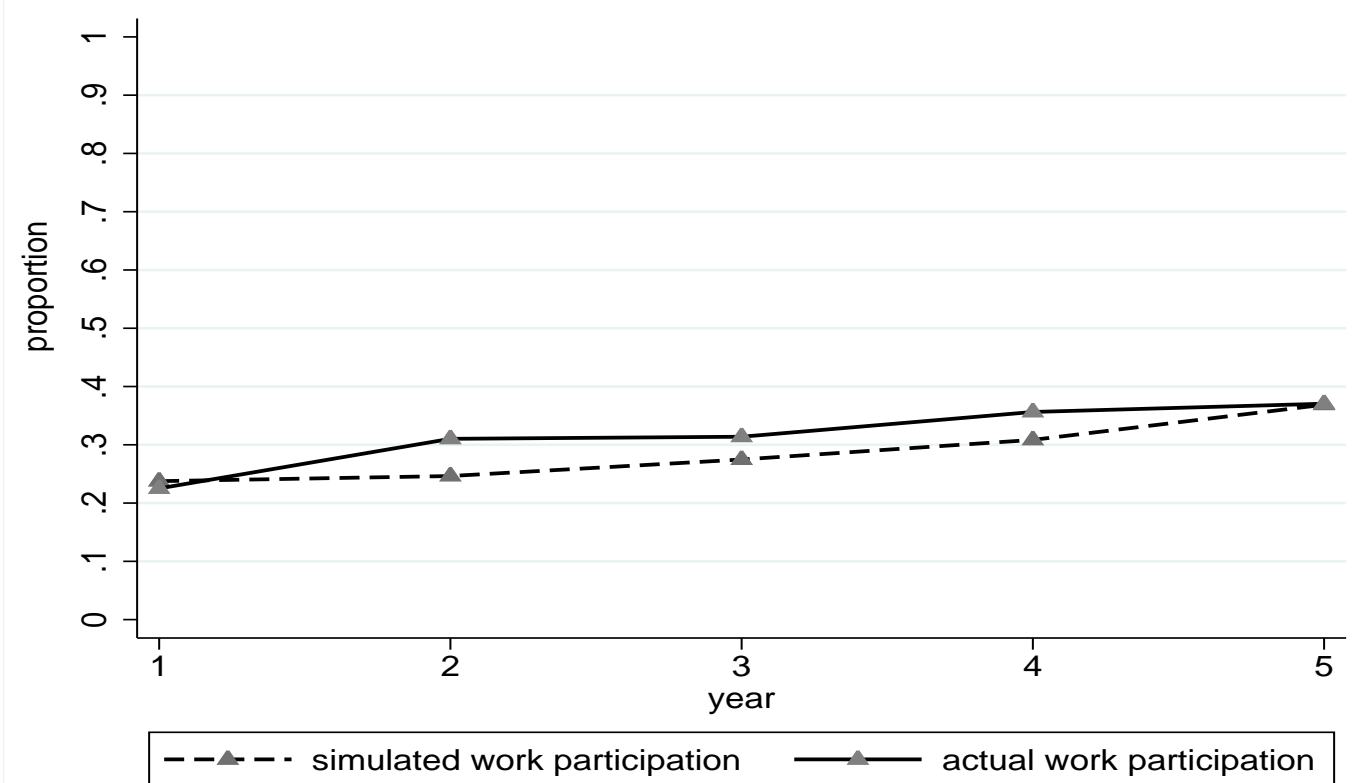

(a) Model Fitness of Work Decision

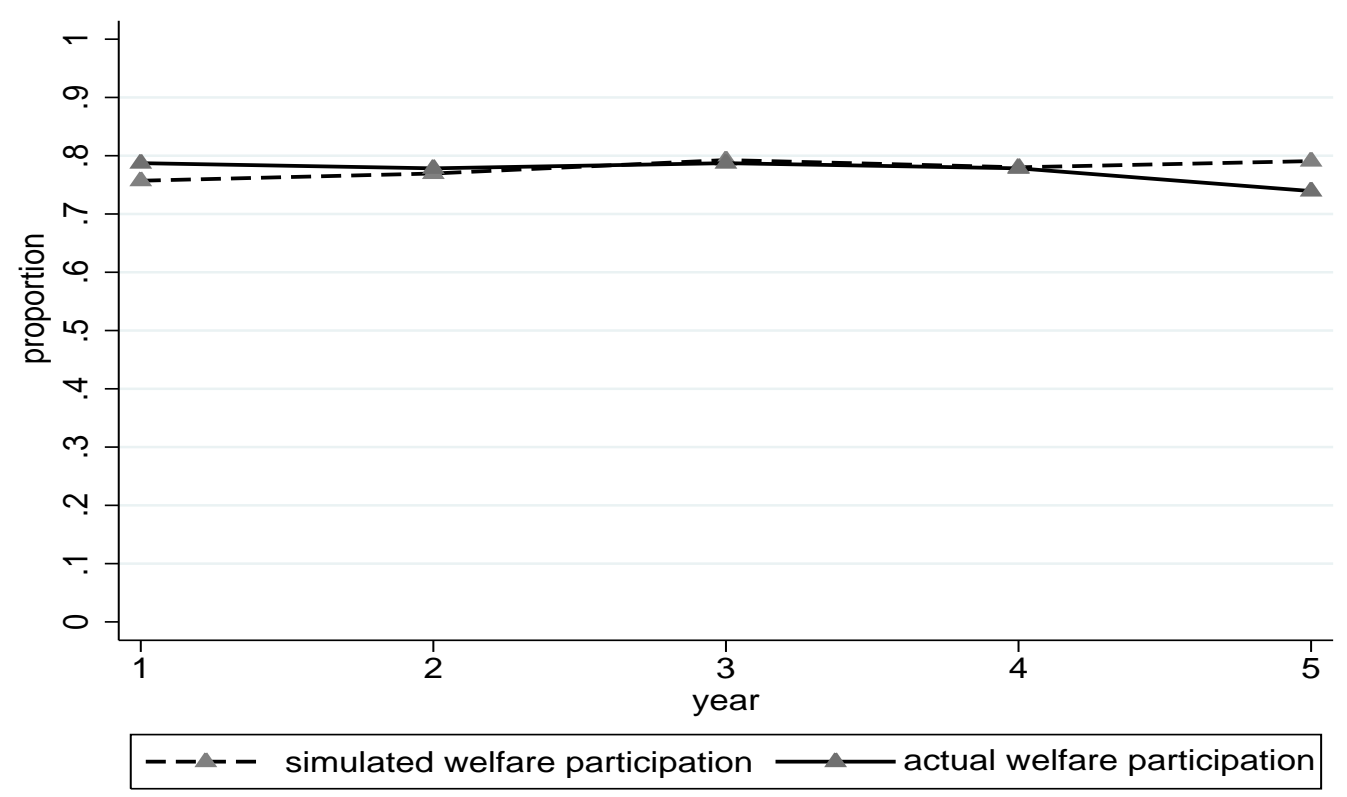

(b) Model Fitness of Welfare Decision 
Figure 3: Participation and Attainment of Different Types

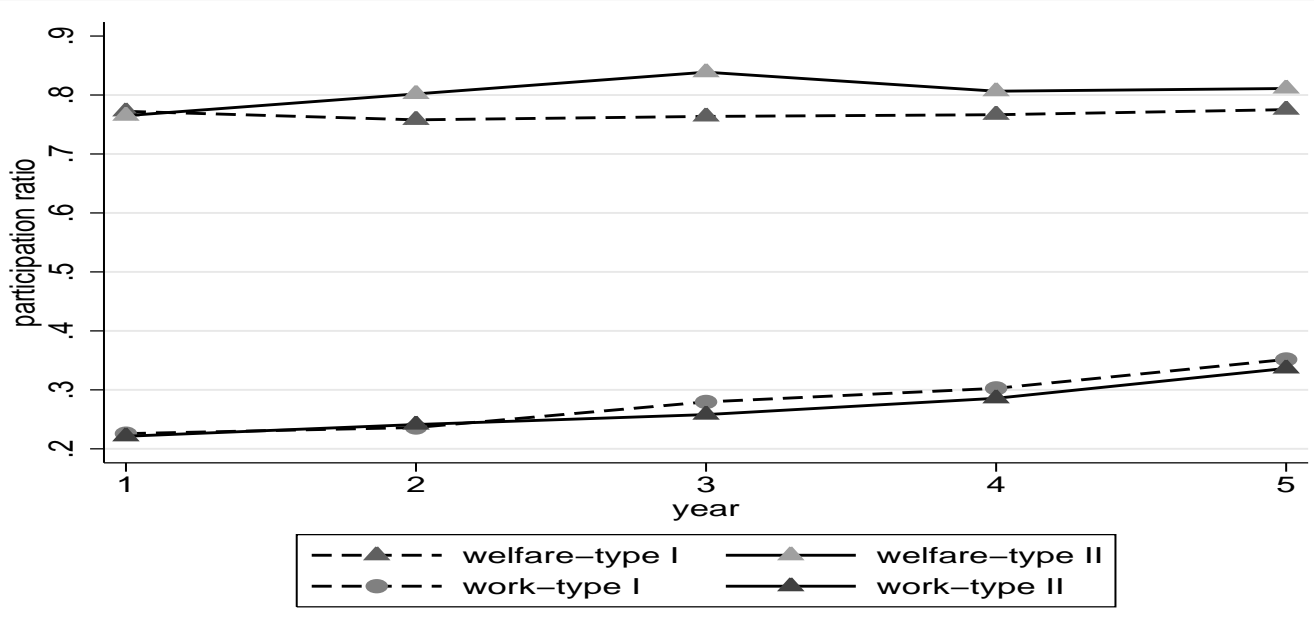

(a) Welfare Use and Work

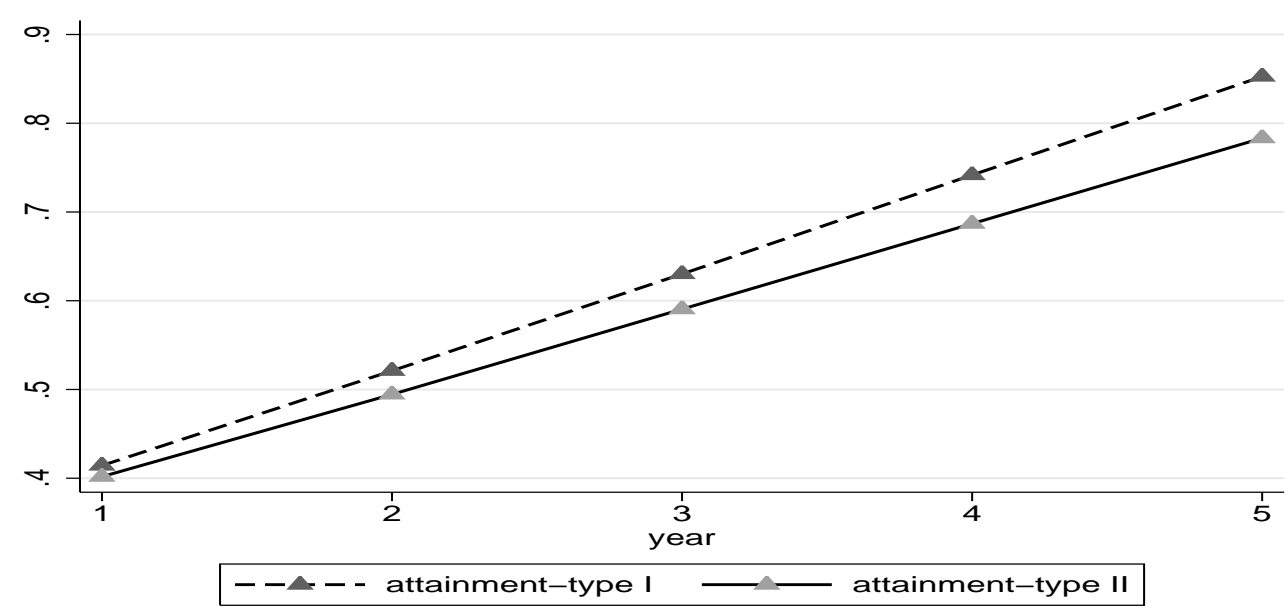

(b) Attainment 
Figure 4: Effect of Time Limit on Welfare and Work Requirement

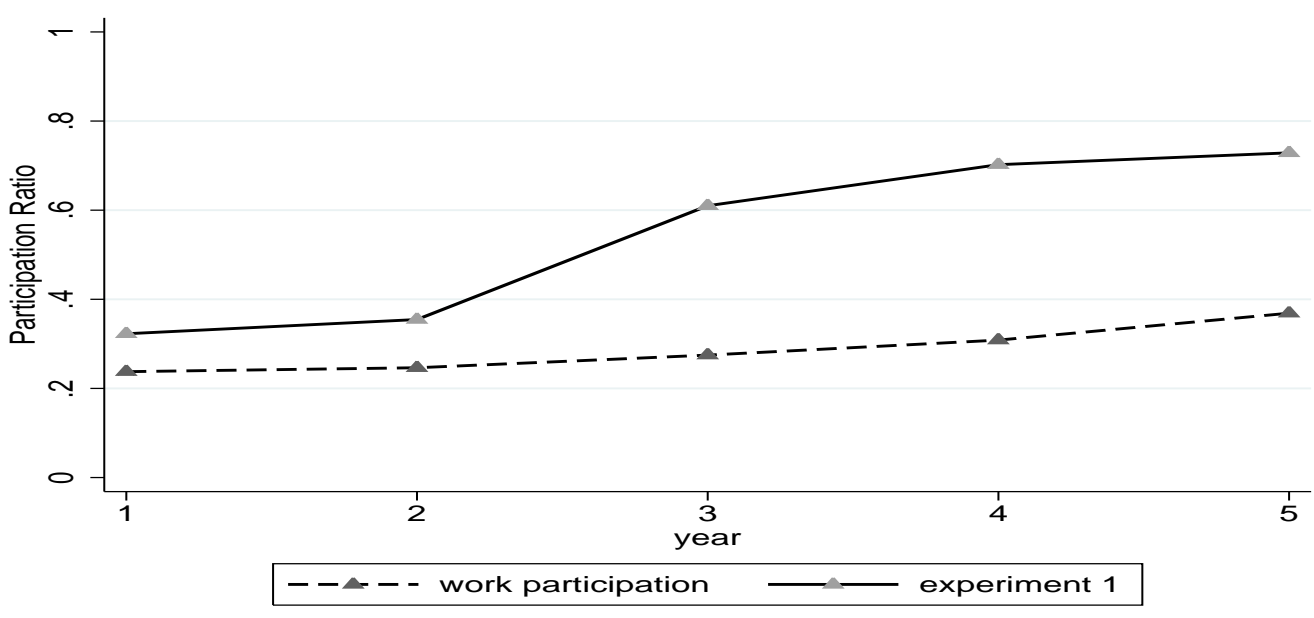

(a) Effect of Policy Change on Work Decision

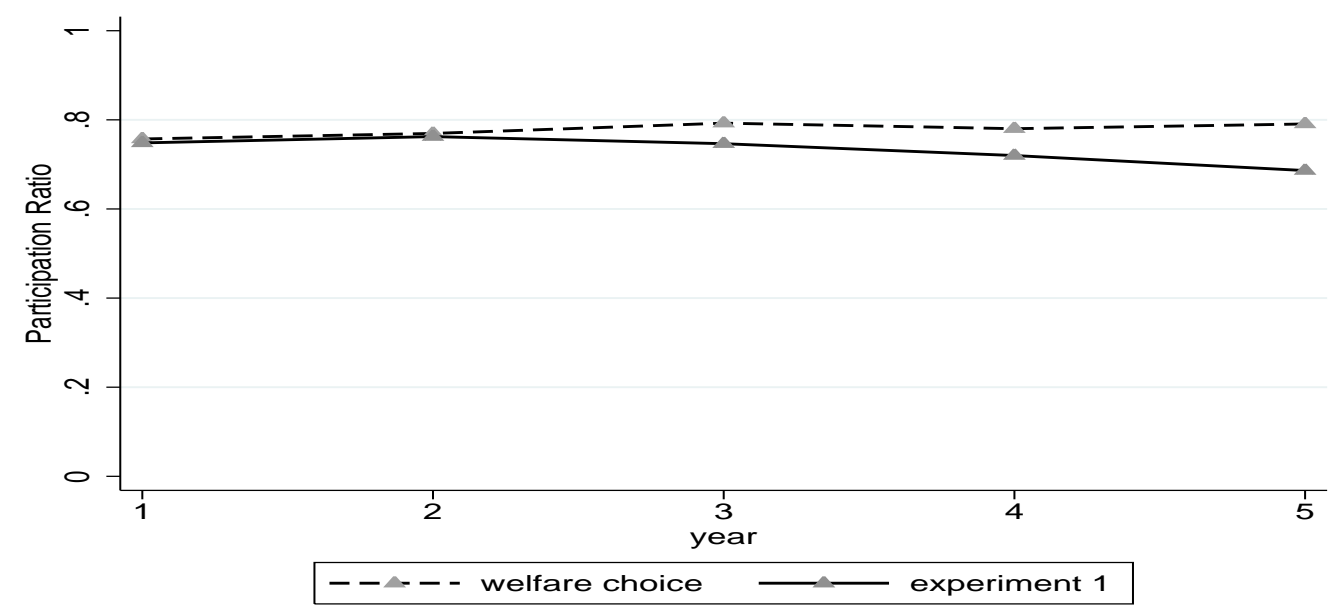

(b) Effect of Policy Change on Welfare Decision

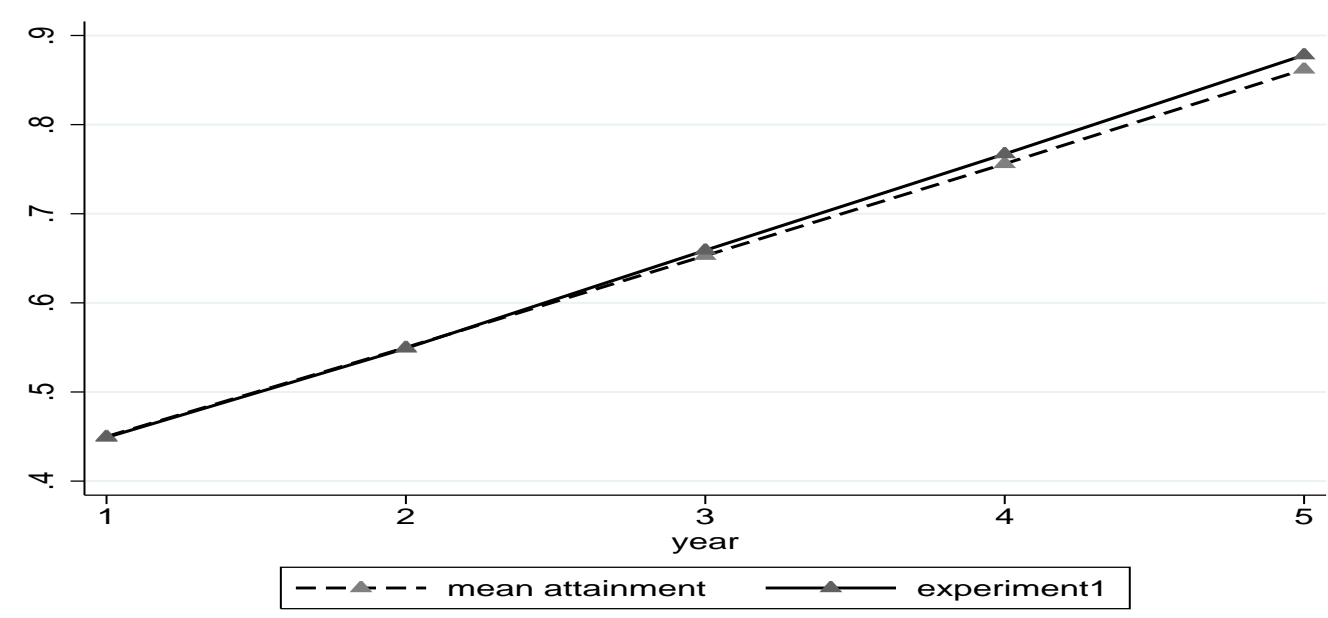

(c) Effect of Policy Change on Children's Ability 
Figure 5: Effect of Taking Off Welfare Tax

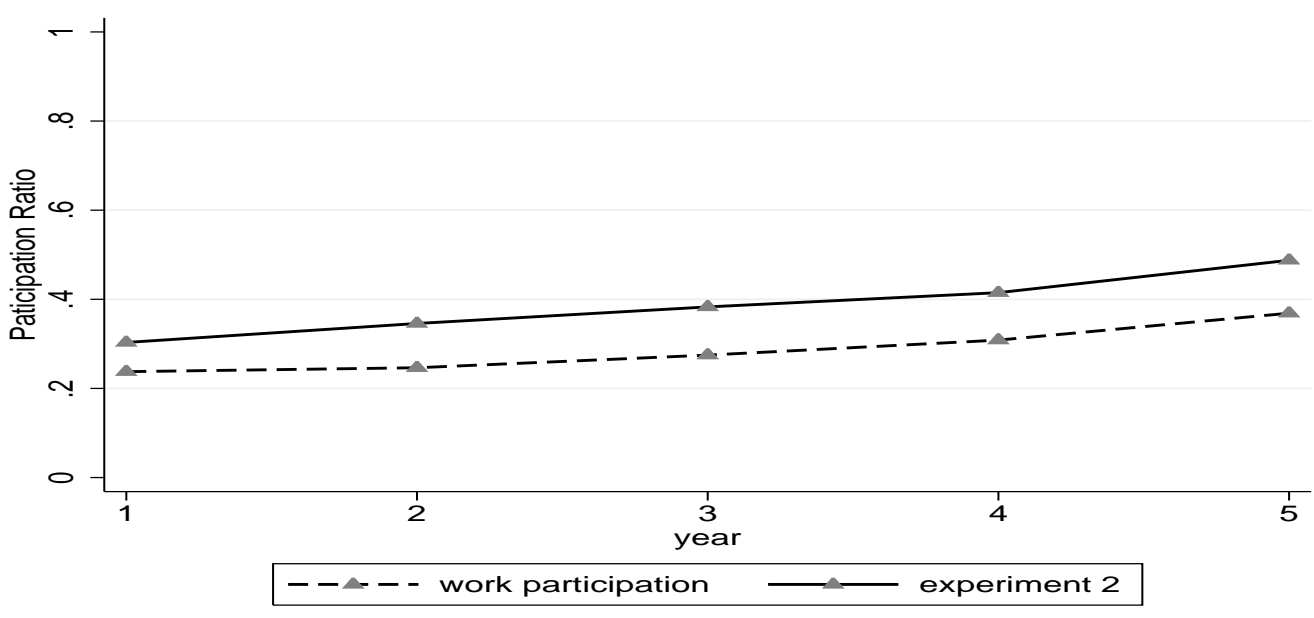

(a) Effect of Policy Change on Work Decision

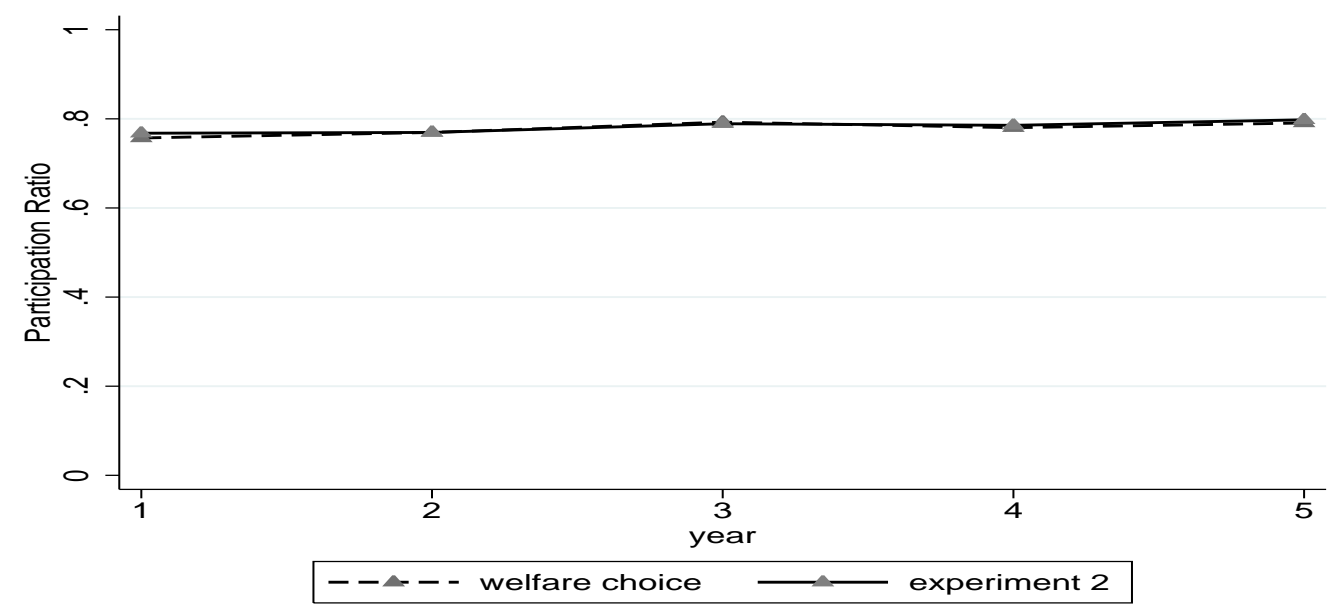

(b) Effect of Policy Change on Welfare Decision

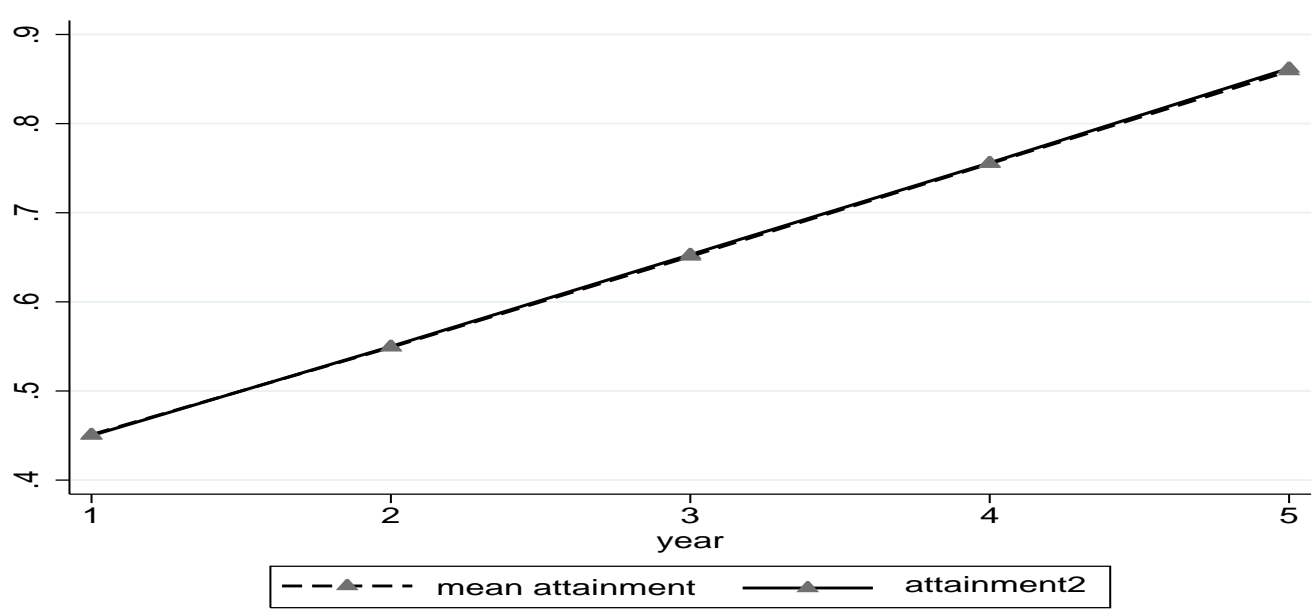

(c) Effect of Policy Change on Children's Ability 
Figure 6: Effect of Maternity Leave Policy

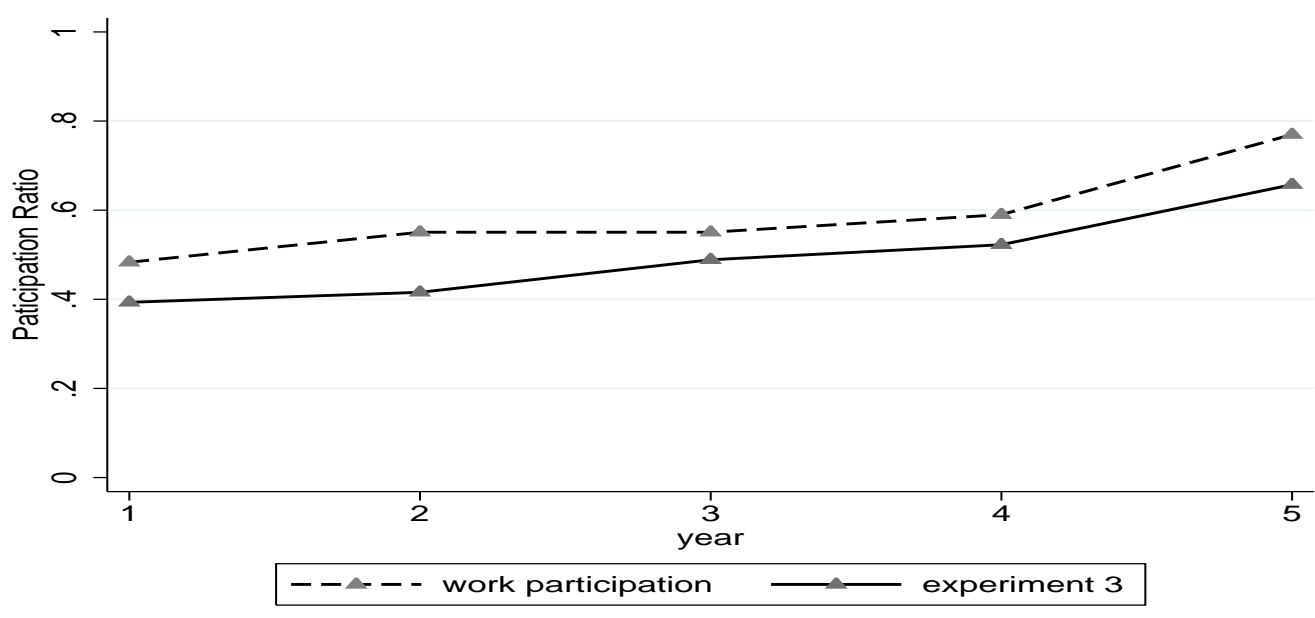

(a) Effect of Policy Change on Work Decision

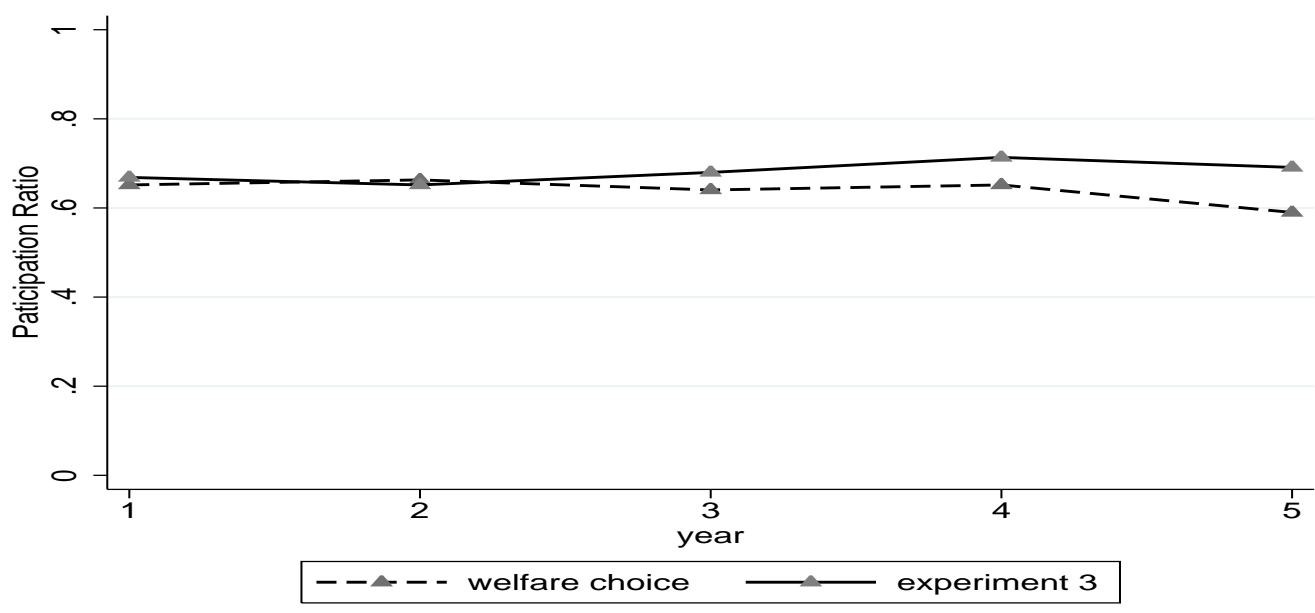

(b) Effect of Policy Change on Welfare Decision

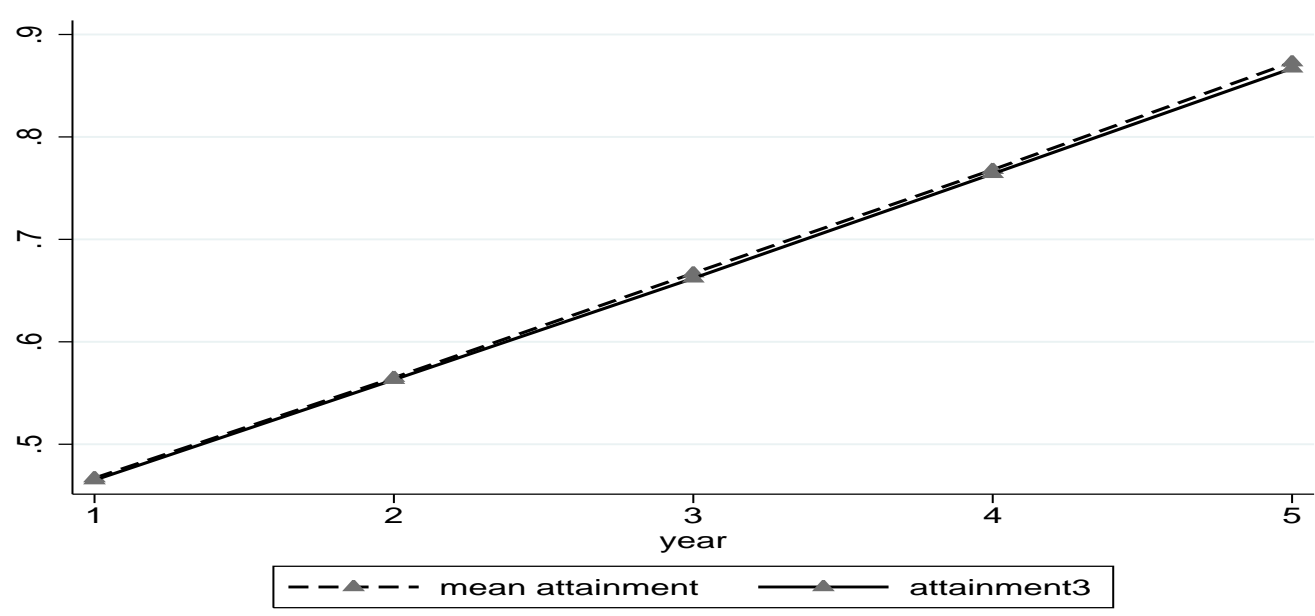

(c) Effect of Policy Change on Children's Ability 


\section{Appendix}

\section{A.1 Solution to the Mother's Optimization Problem}

The mother's optimization problem is solved recursively from the final period $T$. The rationale is as follows: In order to make a choice at $T-1$, a mother calculates the expected value of her choice at period $T$, given that her choice at $T-1$ is $j$. That is, at the beginning of period $T-1$, the mother chooses $d_{j T-1}$ by calculating

$$
V\left(S_{T-1}, \epsilon_{T-1}\right)=\max _{j}\left\{U_{T-1}^{j}+d_{j T-1} \epsilon_{j T-1}+\beta E_{\epsilon} V\left(S_{T}, \epsilon_{T} \mid S_{t-1}, d_{j t-1}\right)\right\} .
$$

In order to do this, first the mother must calculate

$$
\begin{aligned}
E_{\epsilon} V\left(S_{T}, \epsilon_{T}\right) & =\max _{d_{j T}} E_{\epsilon}\left(V_{T}^{1}, V_{T}^{2}, V_{T}^{3}, V_{T}^{4}, V_{T}^{5}, V_{T}^{6} \mid S_{T-1}, d_{T-1}\right) \\
& =\sum_{k} \operatorname{Pr}\left(S_{T}, d_{k T}=1\right) U_{T}^{k}
\end{aligned}
$$

Now, returning to period $T-2$, before she can decide $d_{T-2}$ she needs to know the alternative-specific value functions for every feasible $S_{T-2}^{j}$, and so forth, until she arrives at the current period $t$.

\section{A.2 Discussion of Sampling Variation Between Our Study and Bernal}

\section{and Keane (2010 and 2011)}

Bernal (2008) finds that mothers' employment decisions are detrimental to children's outcomes, which is completely opposite to our results. She uses a sample of children born to two-parents families. Thus in these two situations (two-parent v. one-parent families), rearing technologies are different. However, it is puzzling to us that, using a similar sample of children, Bernal and Keane (2010 and 2011) (referred to as B\&K hereafter) find negative employment effects while we find positive ones. We investigate the reasons for 
this disagreement in results by concentrating on the three dimensions where our paper differs from theirs.

The first main difference is the focus of analysis. In this paper, we look at the effects of welfare use and employment on children's cognitive outcomes, while B\&K investigate the effects of child care. Since the common data source, Children of NLSY 79 mothers, only provides annual child care information for the first three years, B\&K use employment as an empirical proxy for child care. Using employment as a proxy for child care in our context can be problematic, as formal child care provision for less-educated mothers (one of the dimensions where our samples differ, as discussed below) is highly correlated with participation in the welfare program (for example, through the JOBS program). In our sample, regardless of work status, mothers on welfare are more likely to use formal care, if they ever use care at all (25 percent for mothers on welfare as opposed to 20 percent for those who are not on welfare). Also, 17 percent of B\&K's sample are who use formal child care but do not work (see B\&K, 2011: Figure 1, or Section 5.3). In our less-educated mothers sample, 26 percent of children-quarters are of mothers who did not work but had used both welfare and formal care.

It is highly likely that part of the benefit of formal child care (see B\&K, 2011: Section 6.8) for welfare mothers is obtained through welfare program-related child care provision. As a result, it may be improper to discuss the effects of child care on low-skilled groups without simultaneously taking welfare use into account. In this sense, our research complements B\&K's in that we control for a separate channel through which child care affects children's outcomes. Furthermore, as late as 1992, welfare use guaranteed eligibility for Medicaid, Food Stamps, Head Start, and job training programs. As a result, welfare use provides a much broader package of support for mothers in raising their children. This, we think, explains why our welfare use coefficient shows a positive effect for most of our sample children.

In addition to the different focus of research, our paper also has a different sample of children. The choice of outcome variable is the first reason for this discrepancy. In this paper we focus only on one outcome (PIAT-Math), while their dependent variable comprises three outcomes: PIAT-Read, PIAT-Math and PPVT. In other words, a child may be included in a sample as many as three times in B\&K or Bernal (2008). This practice 
significantly increases the sample size of B\&K from 1,464 observations to 3,787 observations. We use PIAT-math test scores as our primary measure of attainment primarily because they have been shown to be predictors of not only later math scores but also overall academic achievement in general (see Claessens, Duncan and Engel, 2009; Duncan et al., 2004). Moreover we can show that our result are robust when we use non-Math test scores as our outcome measures.

The second reason for different sample sizes is the sampling restrictions we impose, in terms of the marital and education status of the mothers. We focus only on single mothers who are less educated (defined empirically as having received no more than 12 years of schooling), while the B\&K sample includes all single mothers. We use a sample of less-educated mothers because we believe better-educated mothers are not relevant to our study, since our concern is the effect of welfare use. It is well known that mothers who are relatively better educated are much less likely to use welfare. In our sample, 79 percent single mothers with, at most, high school education, used welfare at some point, while the ratio for single mothers with at least some college education is only 40 percent. If they have ever used welfare, the latter group is also on welfare for much shorter period of time (8 quarters as opposed to 13 quarters for the former group). Moreover, better educated mothers tend to work much more: 90 percent of women with more than 12 years of schooling have worked, and conditional on working, on average, they have worked for 14 quarters. In our sample, only 74 percent of mothers have reported positive hours of work for an average of 10 quarters. (Note that in Table 1, work is defined as having reported more than 500 hours of work per year.)

In sum, usage of multiple test scores as a unit of observation increases their sample significantly; while the sampling variations imply that they include better educated mothers. Both strategies have advantages and disadvantages. Given that both the B\&K papers and our study find that a marginal employment effect is decreasing as children's innate ability increases, one possible explanation for the difference in results is that mothers with better education (and higher AFQT scores, which itself is highly correlated with the mothers' own education levels) that are captured by B\&K's sample have their time effects outweigh the role model effects. Specification 4.5 in Table A-9 of Chyi and Ozturk (2012) confirms this conjecture. It expands the sample by including better-educated 
single mothers to estimate the marginal effects of the baseline model. ${ }^{\mathrm{A}-1}$ As can be seen, the effects of mothers' work decisions become negative for children with higher observed innate abilities, which actually corresponds to B\&K.

The third difference is that they include many more regressors than we do. In particular, they have the following regressors that we do not: (1) mothers' work experiences prior to their children's birth, including whether they have ever worked and any quarters of work prior to their children's birth; (2) mothers who may not have AFQT scores (with a dummy indicator for mothers with missing AFQTs); and (3) many of the regressors are allowed to interact with the work/child care variables. Please see Table A-1 for a complete list.

To understand how and if differences in samples and models result in the differences between our findings, we attempt to first replicate the B\&K models using our sample and then estimate our models using their sampling methods. Some of the techniques used by $\mathrm{B} \& \mathrm{~K}$ to fill in missing data are not transparent, hence we were unable to replicate their entire sample and were about 700 observations short. So we thus asked Raquel Bernal to provide us with her data and she kindly sent us the identifiers for the children in her sample so that we can compare the models and effects of sampling strategies using their data. Table A-1 reports the estimates of the following reduced-form outcome equation with various samples and regressors

$$
O_{t}=A_{0}+\gamma_{e} E_{t}+A_{0} E_{t} \gamma_{a e}+\left(Y_{t}, V_{2}\right) \beta+\nu
$$

We see that $\left(Y_{t}, V_{2}\right)^{\prime} \beta$ is given as

$$
\begin{aligned}
\left(Y_{t}, V_{2}\right)^{\prime} \beta & =\beta_{1} m+\beta_{2} t+\beta_{3} N \text { sibling }+\beta_{4} \text { always_single } \\
& +\beta_{5} \text { oldest }+\beta_{6} \text { gender }+\beta_{7} \text { Black }+\beta_{8} \text { Hispanic } .
\end{aligned}
$$

Here, $N$ sibling is the number of siblings a child has at time $t$, oldest indicates whether the child is the oldest child in the family, $m$ is the income per household member (capturing

\footnotetext{
${ }^{\mathrm{A}-1}$ However, the sample in that study includes mothers who were sometimes married during the sampling window.
} 
the financial resources available for a child), ${ }^{\mathrm{A}-2}$ and gender, Black and Hispanic are indicators for gender and racial characteristics (where gender=1 if female, Black=1 if Black, Hispanic=1 if Hispanic). The data used in our paper are for any mothers who was single at any time in the first five years after the child's birth. We include an indicator that takes the value of 1 if a mother has always been single during this period (always_single). In this setup, $\nu$ is the unobserved shock, and $\delta, \gamma$ and $\beta$ are the vectors of coefficients to be estimated.

Table A-2, which will be the main focus of the discussion below, collects the marginal effects estimates from these models given children's different observed innate ability levels $\left(A_{0}\right)$.

Specification 1 uses the same work and child care definition as B\&K. It also has the same regressors as those in $\mathrm{B} \& \mathrm{~K}$ and uses the same sample that is used by $\mathrm{B} \& \mathrm{~K}$. As can been seen in the marginal effects in Table A-2, we can successfully recreate the negative employment effects acquired by them. Therefore, the differences between our results have to lie in the above mentioned differences in our sampling strategy.

Specification 2 is identical to Specification 1, except that we use our definition of work. That is, we exclude those who had used child care but never reported positive hours of work. As can be seen from Table A-2, both mean and median marginal effects of employment are now positive. There is undoubtedly significant empirical consequence to including this type of child care as employment. In fact, it can be reasonably argued that this group of mothers (who did not work while having used child care) may have physical or mental conditions (for example, drug use or disability) that prevent them from working or taking care of their own children.

Specification 3 uses the same work and child care definition and regressors as B\&K, but uses our sample (hence including mothers who have better education). As can be seen from Table A-2, although no longer significant, the mean and median effects are still negative. We take this as an indication that our different sampling strategy is not the main reason for the different signs in the employment effects of the two studies.

Finally, Specification 4 tries to gauge the importance of the inclusion of different regressors. After running models with exhaustive combinations of various regressors,

A-2 It can be expressed as $m=\sum_{k=1}^{T} \frac{\left(M_{k}+W_{k} I_{k}^{w}+E_{k} w_{k}\right)}{\text { household size }}$. 
we find that the absence of prior work experiences in our independent variables actually accounts for a significant part of the positive employment effect. Specification 4 in Table A-2 lists the estimation results using B\&K's sample and definition of work. However, we do not include a prior work experience dummy nor quarters worked prior to the child's birth. It can be seen that both the median and the mean effects are significantly positive now.

Comparisons of Specifications 1 to 4 show that the most important sources of variation between $\mathrm{B} \& \mathrm{~K}$ and our results come from (1) B\&K's inclusion in employment figures of people who used child care but have never worked, and (2) inclusion of prior work experience as a regressor. 
Table A-1: Comparing B\&K and Our Results

\begin{tabular}{|c|c|c|c|c|}
\hline Specification & $\begin{array}{c}1 \\
\text { B\&K's Work, } \\
\text { Regressors and } \\
\text { Sample }\end{array}$ & $\begin{array}{c}2 \\
\text { Our Work, } \\
\text { B\&K's Regressors and } \\
\text { Sample }\end{array}$ & $\begin{array}{c}3 \\
\text { B\&K's Work and } \\
\text { Regressors, } \\
\text { Our Sample }\end{array}$ & $\begin{array}{c}4 \\
\text { No Prior Work, } \\
\text { B\&K's Work and } \\
\text { Sample }\end{array}$ \\
\hline \multicolumn{5}{|l|}{ Mother's Decision } \\
\hline $\begin{array}{l}E \\
\left(\gamma_{e}\right) \\
\text { Observed Covaria }\end{array}$ & $\begin{array}{c}-0.176^{* * *} \\
(0.029) \\
\end{array}$ & $\begin{array}{c}-0.095^{* * *} * \\
(0.015)\end{array}$ & $\begin{array}{c}0.016 \\
(0.021)\end{array}$ & $\begin{array}{c}0.360 * * * \\
(0.023)\end{array}$ \\
\hline $\begin{array}{l}\text { Income } \\
\text { Per Child } \dagger\end{array}$ & $\begin{array}{c}0.004 * * \\
(0.002)\end{array}$ & $\begin{array}{c}0.003 \\
(0.002)\end{array}$ & $\begin{array}{c}0.030 * * * \\
(0.002)\end{array}$ & $\begin{array}{l}-0.007 \\
(0.010)\end{array}$ \\
\hline Age Taking Test & $\begin{array}{c}-0.048 * * * \\
(0.003)\end{array}$ & $\begin{array}{c}-0.043 * * * \\
(0.003)\end{array}$ & $\begin{array}{l}-0.003 \\
(0.002)\end{array}$ & $\begin{array}{c}-0.035^{* * * *} \\
(0.013)\end{array}$ \\
\hline $\begin{array}{l}\text { Number of } \\
\text { Siblings }\end{array}$ & $\begin{array}{c}-1.396 * * * \\
(0.062)\end{array}$ & $\begin{array}{c}-1.157 * * * \\
(0.055)\end{array}$ & $\begin{array}{c}-1.648 * * * \\
(0.044)\end{array}$ & $\begin{array}{c}-0.749 * * * \\
(0.248)\end{array}$ \\
\hline $\begin{array}{l}\text { Oldest } \\
\text { Child }\end{array}$ & $\begin{array}{c}1.919 * * * \\
(0.142)\end{array}$ & $\begin{array}{c}2.042 * * * \\
(0.142)\end{array}$ & $\begin{array}{c}1.770 * * * \\
(0.102)\end{array}$ & $\begin{array}{c}1.914 * * * \\
(0.604)\end{array}$ \\
\hline \multicolumn{5}{|l|}{ Our $A_{0}$} \\
\hline $\begin{array}{l}\text { Birth } \\
\text { Weight }\end{array}$ & $\begin{array}{c}0.953 * * * \\
(0.234)\end{array}$ & $\begin{array}{c}1.551 * * * \\
(0.231)\end{array}$ & $\begin{array}{c}2.620 * * * \\
(0.174)\end{array}$ & $\begin{array}{c}3.049 * * * \\
(0.985)\end{array}$ \\
\hline AFQT & $\begin{array}{c}2.806 * * * \\
(0.099)\end{array}$ & $\begin{array}{c}3.318 * * * \\
(0.089)\end{array}$ & $\begin{array}{c}2.249 * * * \\
(0.078)\end{array}$ & $\begin{array}{c}1.821 * * * \\
(0.441)\end{array}$ \\
\hline $\begin{array}{l}\text { High School } \\
\text { Dummy }\end{array}$ & $\begin{array}{c}3.351 * * * \\
(0.174)\end{array}$ & $\begin{array}{c}3.494 * * * \\
(0.180)\end{array}$ & $\begin{array}{c}2.564 * * * \\
(0.128)\end{array}$ & $\begin{array}{c}2.058 * * * \\
(0.776)\end{array}$ \\
\hline \multicolumn{5}{|l|}{ Also in B\&K's $A_{0}$} \\
\hline Gender & $\begin{array}{c}3.286 * * * \\
(0.123)\end{array}$ & $\begin{array}{c}3.212 * * * \\
(0.123)\end{array}$ & $\begin{array}{c}1.401 * * * \\
(0.096)\end{array}$ & $\begin{array}{c}2.748 * * * \\
(0.519)\end{array}$ \\
\hline Black & $\begin{array}{c}-5.326 * * * \\
(0.190)\end{array}$ & $\begin{array}{c}-7.393 * * * \\
(0.189)\end{array}$ & $\begin{array}{c}-5.158 * * * \\
(0.147)\end{array}$ & $\begin{array}{c}-6.715 * * * \\
(0.955)\end{array}$ \\
\hline Hispanic & $\begin{array}{c}-5.880 * * * \\
(0.283)\end{array}$ & $\begin{array}{c}-7.960 * * * \\
(0.275)\end{array}$ & $\begin{array}{c}-6.105 * * * \\
(0.189)\end{array}$ & $\begin{array}{c}-8.638 * * * \\
(1.185)\end{array}$ \\
\hline $\begin{array}{l}\text { Mother's } \\
\text { Age }\end{array}$ & $\begin{array}{c}-3.925 * * * \\
(0.276)\end{array}$ & $\begin{array}{c}-3.098 * * * \\
(0.275)\end{array}$ & $\begin{array}{c}-1.436 * * * \\
(0.212)\end{array}$ & $\begin{array}{c}-2.350 * * \\
(1.150)\end{array}$ \\
\hline $\begin{array}{l}\text { Age } \\
\text { Squared }\end{array}$ & $\begin{array}{c}0.071 * * * \\
(0.005)\end{array}$ & $\begin{array}{c}0.056 * * * \\
(0.005)\end{array}$ & $\begin{array}{c}0.026 * * * \\
(0.004)\end{array}$ & $\begin{array}{c}0.045^{* * *} \\
(0.019)\end{array}$ \\
\hline $\begin{array}{l}\text { Born Before } \\
18\end{array}$ & $\begin{array}{l}-0.041 \\
(0.300)\end{array}$ & $\begin{array}{c}-1.279 * * * \\
(0.305)\end{array}$ & $\begin{array}{c}2.026 * * * \\
(0.222)\end{array}$ & $\begin{array}{l}0.600 \\
(1.223)\end{array}$ \\
\hline $\begin{array}{l}\text { Born After } \\
33\end{array}$ & $\begin{array}{c}-5.988 * * * * \\
(0.545)\end{array}$ & $\begin{array}{c}-3.142 * * * \\
(0.549)\end{array}$ & $\begin{array}{c}1.591 * * * \\
(0.406)\end{array}$ & $\begin{array}{c}-5.717 * * \\
(2.413)\end{array}$ \\
\hline $\begin{array}{l}\text { Worked } \\
\text { Before }\end{array}$ & $\begin{array}{c}0.415 * * * \\
(0.031)\end{array}$ & $\begin{array}{c}0.463 * * * \\
(0.031)\end{array}$ & $\begin{array}{c}0.022 \\
(0.023)\end{array}$ & \\
\hline $\begin{array}{l}\text { Prior Work } \\
\text { Experience }\end{array}$ & $\begin{array}{c}0.822 * * * \\
(0.187)\end{array}$ & $\begin{array}{l}-0.273 \\
(0.171)\end{array}$ & $\begin{array}{c}1.902 * * * \\
(0.141)\end{array}$ & \\
\hline PIAT-Read & $\begin{array}{c}6.846 * * * \\
(0.127)\end{array}$ & $\begin{array}{c}6.845 * * * \\
(0.126)\end{array}$ & $\begin{array}{c}5.061 * * * \\
(0.091)\end{array}$ & $\begin{array}{c}6.985 * * * \\
(0.539)\end{array}$ \\
\hline PPVT & $\begin{array}{c}-15.870 * * * \\
(0.135)\end{array}$ & $\begin{array}{c}-16.162 * * * \\
(0.141)\end{array}$ & $\begin{array}{c}-13.352 * * * \\
(0.103)\end{array}$ & $\begin{array}{c}-17.648^{* * *} \\
(0.580)\end{array}$ \\
\hline$\phi_{e}$ & $\begin{array}{c}5.747 * * * \\
(0.570)\end{array}$ & $\begin{array}{c}2.064 * * * \\
(0.236)\end{array}$ & $\begin{array}{c}1.871 * * * \\
(0.404)\end{array}$ & $\begin{array}{c}-6.456^{* * *} * \\
(1.876)\end{array}$ \\
\hline Constant & $\begin{array}{c}137.151 * * * \\
(4.199)\end{array}$ & $\begin{array}{c}125.793 * * * \\
(4.213)\end{array}$ & $\begin{array}{c}97.594 * * * \\
(3.238)\end{array}$ & $\begin{array}{c}111.574 * * * \\
(17.647)\end{array}$ \\
\hline
\end{tabular}

\footnotetext{
- All specifications include the state fixed effect, interactions between $A_{0}$ and $E$, and dummies for missing AFQT and birth weight. To save space, they are not listed.

${ }^{* * * *}$ : significant at $1 \%$ significance level. ${ }^{* *}$ : significant at $5 \%$ significance level. ${ }^{*}$ : significant at $10 \%$ significance level.

$\dagger$ Measured in thousands real dollars (year 2000 price deflated by PCED nondurable).
} 
Table A-2: Marginal Effects Calculated (Based on Table A-1)

\begin{tabular}{|c|c|c|c|c|}
\hline Specification & $\begin{array}{c}1 \\
\text { B\&K's Work, } \\
\text { Regressors and } \\
\text { Sample }\end{array}$ & $\begin{array}{c}2 \\
\text { Our Work and } \\
\text { B\&K's Regressors and } \\
\text { Sample }\end{array}$ & $\begin{array}{c}3 \\
\text { B\&K's Work and } \\
\text { Regressors, } \\
\text { Our Sample }\end{array}$ & $\begin{array}{c}4 \\
\text { No Prior Work, } \\
\text { B\&K's Work and } \\
\text { Sample }\end{array}$ \\
\hline \multicolumn{5}{|c|}{ Marginal Effects of Employment $=\gamma_{e}+\sum_{i} \gamma_{a e i} V_{1 i}$} \\
\hline $1 \%$ & $\begin{array}{c}0.283 * * * \\
(0.059)\end{array}$ & $\begin{array}{c}0.641 * * * \\
(0.041)\end{array}$ & $\begin{array}{c}0.474 * * * \\
(0.041)\end{array}$ & $\begin{array}{c}0.845^{* * *} * \\
(0.056)\end{array}$ \\
\hline $25 \%$ & $\begin{array}{l}-0.015 \\
(0.039)\end{array}$ & $\begin{array}{c}0.269 * * * \\
(0.031)\end{array}$ & $\begin{array}{c}0.097 * * * \\
(0.031)\end{array}$ & $\begin{array}{c}0.508 * * * \\
(0.035)\end{array}$ \\
\hline $50 \%$ & $\begin{array}{c}-0.127 * * * \\
(0.038)\end{array}$ & $\begin{array}{c}0.078 * * * \\
(0.028)\end{array}$ & $\begin{array}{l}-0.025 \\
(0.028)\end{array}$ & $\begin{array}{c}0.388 * * * \\
(0.034)\end{array}$ \\
\hline $75 \%$ & $\begin{array}{c}-0.284 * * * \\
(0.037)\end{array}$ & $\begin{array}{c}-0.115^{* * *} \\
(0.026)\end{array}$ & $\begin{array}{c}-0.120 * * * \\
(0.027)\end{array}$ & $\begin{array}{c}0.240 * * * \\
(0.034)\end{array}$ \\
\hline $99 \%$ & $\begin{array}{c}-0.774 * * * \\
(0.045)\end{array}$ & $\begin{array}{c}-0.664 * * * \\
(0.023)\end{array}$ & $\begin{array}{c}-0.456^{* * *} \\
(0.039)\end{array}$ & $\begin{array}{c}-0.177 * * * \\
(0.038)\end{array}$ \\
\hline Mean & $\begin{array}{c}-0.164 * * * \\
(0.039)\end{array}$ & $\begin{array}{l}0.067 * \\
(0.028)\end{array}$ & $\begin{array}{l}-0.010 \\
(0.028)\end{array}$ & $\begin{array}{c}0.367 * * * \\
(0.033)\end{array}$ \\
\hline
\end{tabular}

All specifications also include state and cohort fixed effects.

${ }^{* * *}$ : significant at $1 \%$ significance level. ${ }^{* *}$ : significant at $5 \%$ significance level. ${ }^{*}$ : significant at $10 \%$ significance level. 